\title{
Testing the Stochastic Dynamic Methodology (StDM) as a management tool in a shallow temperate estuary of south Europe (Mondego, Portugal)
}

\author{
Pedro Silva-Santos ${ }^{a, *}$, Miguel Ângelo Pardal ${ }^{b}$, Ricardo Jorge Lopes ${ }^{c}$, Tiago Múrias ${ }^{c}$, \\ João Alexandre Cabral ${ }^{a}$ \\ a Laboratory of Applied Ecology, CETAV/CITAB, Department of Biological and Environmental Engineering, University of Trás-os-Montes e \\ Alto Douro, 5000-911 Vila Real, Portugal \\ $\mathrm{b}$ IMAR (Institute of Marine Research), Department of Zoology, University of Coimbra, 3004-517 Coimbra, Portugal \\ c CIBIO, Research Center in Biodiversity and Genetic Resources, University of Porto, Campus Agrário de Vairão, Rua Padre Armando \\ Quintas-Crasto, 4485-661 Vairão, Portugal
}

\section{A R T I C L E I N F O}

Article history:

Received 1 August 2006

Received in revised form

4 September 2007

Accepted 10 September 2007

Published on line 24 October 2007

Keywords:

Stochastic Dynamic Methodology

Eutrophication

Estuarine ecosystems

Trophic interactions

Management tools

\section{A B S T R A C T}

A long-term monitoring program has been carried out since the early 1990s in the Mondego estuary, on Portugal's west coast, which is presently under heavy human pressure. In this shallow warm-temperate estuary, a significant macroalgal proliferation has been observed, which is a clear sign of nutrient enrichment. As a result of competition with algae, the extension of the seagrass meadows (mainly Zostera noltii) has been reduced. The present paper examined the applicability of a holistic Stochastic Dynamic Methodology (StDM) in predicting the tendencies of trophic key-components (macrophytes, macroalgae, benthic macroinvertebrate and wading birds) as a response to the changes in estuarine environmental conditions. The StDM is a sequential modelling process developed in order to predict the ecological status of changed ecosystems, from which management strategies can be designed. The data used in the dynamic model construction included true gradients of environmental changes and was sampled from January 1993 to September 1995 and from December 1998 to December 2005. The dynamic model developed was preceded by a conventional multivariate statistical procedure performed to discriminate the significant relationships between the selected ecological components. The model validation was based on independent data collected from January 1996 to January 1997 and from February 1999 to April 2000 for all the state variables considered. Overall, the simulation results are encouraging since they seem to demonstrate the StDM reliability in capturing the trophic dynamics of the studied estuary, by predicting the behavioural pattern for the most part of the components selected, with a focus on the Zostera noltii meadows recovery after the implementation of important management measures.

(c) 2007 Elsevier B.V. All rights reserved.

\footnotetext{
* Corresponding author. Tel.: +351 259350 239; fax: +351 259350266.

E-mail address: pedross@utad.pt (P. Silva-Santos). 


\section{Introduction}

Likewise other coastal systems worldwide, the Mondego estuary has been exhibiting clear evidence of eutrophication as a result of nutrient loading from several industries and agricultural run-off, mainly from rice fields (Marques et al., 2003; Martins et al., 2001; Norkko et al., 2000; Wooldridge and Callahan, 2000; Pardal et al., 2000, 2004; Cloern, 2001; Sfriso et al., 2001; Cardoso et al., 2004a; Dolbeth et al., 2003; Ferreira et al., 2004). As a result of competition with algae, the extension of the seagrass meadows (mainly Zostera noltii) has been reduced, which caused a shift in primary producers (Dolbeth et al., 2003; Cardoso et al., 2004a) and changes in the energy flow at the secondary and tertiary levels, including the upper trophic level organisms dominated by wading birds (Cabral et al., 1999; Lopes et al., 2002). As a consequence of the eutrophication process, the seagrass bed ( $Z$. noltii) of Mondego estuary has almost disappeared, reducing in extent from 15 ha in the early 1980s to 0.02 ha in the mid-1990s (e.g. Dolbeth et al., 2003; Marques et al., 2003; Pardal et al., 2004; Lillebø et al., 2005). The Mondego estuary is warm-temperate in a region with a basic Mediterranean climate. The terminal part of the estuary consists of two arms, north and south, that surround the Murraceira island (Fig. 1). The two arms of the estuary are hydrologically very different. The north arm is deeper, and

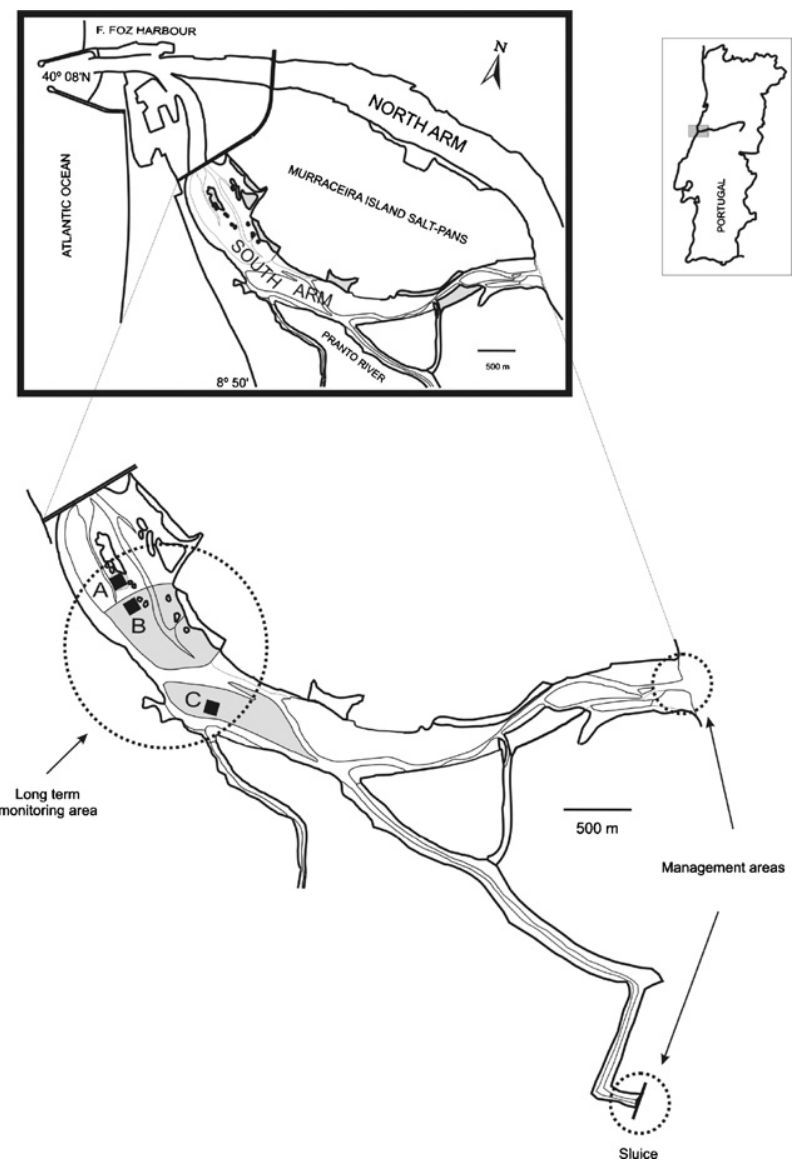

Fig. 1 - Location of the sampling areas in the south arm of the Mondego estuary: (A) Zostera noltii meadows, (B) intermediate area, and (C) most eutrophic area. most of the fresh water discharge from the river flows through it. The south arm is almost silted up in the upstream areas and the water circulation in this arm is almost entirely due to tides and to the freshwater input of a tributary, the Pranto river (Fig. 1). In 1998, some mitigation measures were implemented aiming the recover of the $Z$. noltii meadows. The hydraulic regime was improved on the south arm riverhead by enlarging the connection between the two arms, allowing water to flow from the north arm at all high tide situations. Additionally, nutrient loadings from upstream agricultural areas were minimised due to better management and appropriate sluice handling (Lillebø et al., 2005).

The most popular tools to assess how anthropogenic environmental changes will affect the abundance and richness of species in disturbed communities have been biological indices, which reduce the dimensionality of complex ecological data sets to a single univariate statistic and/or ordination methods (Kareiva et al., 1993; Andreasen et al., 2001; Pardal et al., 2004). Nevertheless, when a time factor is present within the data, they are unable to estimate, in a comprehensible way, the structural changes when the habitat conditions are substantially changing (Jørgensen and Bernardi, 1997; Pardal et al., 2004). Therefore, ecological integrity studies have been improved by creating dynamic models that simultaneously attempt to capture the structure and the composition in systems affected by long-term environmental disturbances Jørgensen, 1994; Costanza and Voinov, 2001; Chaloupka, 2002; Santos and Cabral, 2003; Cabecinha et al., 2004; Silva-Santos et al., 2006). We learned that development of ecological models requires a consistent knowledge of the functioning of ecosystems (Jørgensen, 1994). When properly developed and tested, they must be applied with insight and with regard to their underlying assumptions. These requirements could result in models capable of simulating conditions that are difficult or impossible to understand otherwise. Nevertheless, we are still facing serious problems in ecological modelling, namely because basic deficiencies exist in ecosystem science. In a reductionistic analytical perspective, the parameter estimation is often the weakest point in modelling (Jørgensen, 1999). This results from the evidence that the characterization of an ecosystem cannot be complete.

Management of coastal and estuarine systems has an increasing need for tools capable to relate environmental variables and system parameters with external factors that affect those systems. The application of ecological modelling synthesizes the pieces of ecological knowledge, emphasizing the need for a holistic view of a certain environmental problem (Brosse et al., 2001; Cabral et al., 2001; Jørgensen, 2001; Voinov et al., 2001; Santos and Cabral, 2003; Cabecinha et al., 2004; Silva-Santos et al., 2006). Since many of the ecosystem phenomenological aspects are holistic, whole-system properties, the main vocation of the Stochastic Dynamic Methodology (StDM) recently developed is a mechanistic understanding of the holistic ecological processes, based on a statistical parameter estimation method (Santos and Cabral, 2003; Cabecinha et al., 2004; Silva-Santos et al., 2006). Our own recent research is based on the premise that the general statistical patterns of ecological phenomena are emergent indicia of complex ecological processes that do indeed reflect the operation of universal law-like mechanisms. The StDM is a sequential 
modelling process developed in order to predict the ecological status of changed ecosystems, from which management strategies can be designed. This methodology was successfully tested in several types of ecological systems, such as mountain running waters (Cabecinha et al., 2004), mediterranean agroecosystems (Santos and Cabral, 2003; Cabral et al., 2007), estuaries (Silva-Santos et al., 2006), and for simulating the impact of socio-economic trends on threatened species (Santos et al., 2007).

In a preliminary deterministic approach, we developed a StDM model to validate simulations of trophic interactions between some relevant biological components (primary producers, benthic macroinvertebrates and wading birds) and physicochemical conditions in an estuarine eutrophication scenario (Silva-Santos et al., 2006). Although these simulations are encouraging, we believe that our present proposal will provide the development of a true management tool, namely taking into account stochastic/random phenomena that characterize the real ecological processes (Van der Meer et al., 1996). Therefore, as an improvement of our previous work, the main objectives of this paper includes not only the validation but also the demonstration of the applicability of StDM in the scope of the ecological monitoring and management carried out in the Mondego estuary. The hypotheses to be tested were: (1) that changes on model construction and conceptualisation, relatively to our previous work (Silva-Santos et al., 2006), increases the accuracy of simulations produced by the StDM and (2) that the stochastic simulation results can be used to help management decisions by predicting the ecological recovery patterns in the Mondego estuary as consequence of the measures implemented in the last years (Lillebø et al., 2005).

\section{Materials and methods}

\subsection{Study site description}

The Mondego estuary (Western Portugal) is $7 \mathrm{~km}$ long and 2-3 km wide, covers an area of 1072 ha and consists of two different arms, north and south, separated by an alluviumformed island (Murraceira Island) (Fig. 1). The construction of harbour facilities has imposed severe changes of this ecosystem since the 1930s, particularly the construction of stonewalls to regulate the main navigation channels and the construction of small water reservoirs for agriculture and aquacultures purposes.

Two main different types of communities were identified in the south arm mudflats (Pardal et al., 2000, 2004; Dolbeth et al., 2003): (1) Z. noltii meadows in downstream areas where the nutrient concentration is lower (Fig. 1, area A). These meadows have a diversified macroinvertebrate assemblage where Hydrobia ulvae represent about $75 \%$ of the total yearly production (Dolbeth et al., 2003); (2) an Enteromorpha dominant community, with the main presence of Cyathura carinata populations, is found in the upstream areas with lower salinity values and higher nutrient concentration in water (Fig. 1, area C). A third area was considered as an intermediate situation (Fig. 1, area B), in terms of nutrient enrichment, to complete the spatial gradient of eutrophication in the Mondego estuary (Marques et al., 2003; Dolbeth et al., 2003; Pardal et al., 2000, 2004). Sampling occurred in these three areas of the south arm (Fig. 1) where, until 1998, water circulation was dependent on tidal activity and on the freshwater input from a tributary, the Pranto River, with the hydrologic flows controlled by a sluice (Fig. 1) and regulated according to the water needs in rice fields in the Mondego valley (Flindt et al., 1997; Pardal et al., 2000; Dolbeth et al., 2003). The freshwater discharge proceeding from the Pranto into the south arm represented an important source of nutrients into the south arm due to fertilizers used in the rice crops (Flindt et al., 1997; Pardal et al., 2000). Although a large part of the south arm intertidal area still remains more or less unchanged, macroalgae blooms have been regularly observed over the last two decades, leading the system under environmental stress by eutrophication processes (Pardal et al., 2000; Dolbeth et al., 2003, 2005; Patrício et al., 2004; Lilleb $\varnothing$ et al., 2005). A previous study, conducted by Martins et al. (2001) between January 1993 and January 1997, concluded that hydrodynamics was a major factor controlling macroalgal biomass in the Mondego estuary, which in turn depends on weather conditions (namely dry or wet situations) and river management practices according to the water requirements of the upstream rice crop to avoid fields being water-deficient or flooded.

\subsection{Monitoring program}

In the Mondego estuary, a long-term monitoring program has been carried out since the early 1990s by a research team of IMAR-Institute with respect to: (a) environmental factors, namely inorganic nutrient concentrations in the water column (Flindt et al., 1997; Pardal et al., 2000; Martins et al., 2001); (b) biomass variation and productivity of benthic primary producers (Pardal et al., 2000; Cardoso et al., 2002, 2004b; Ferreira et al., 2004; Dolbeth et al., 2005); (c) seasonal and inter-annual variation of wading birds (Múrias et al., 1996, 1997; Lopes et al., 2005); (d) impacts of macroalgae blooms on macrofaunal communities and waders (Múrias et al., 1996; Martins et al., 1997; Cabral et al., 1999; Lillebø et al., 1999; Pardal et al., 2000; Lopes et al., 2005).

Physicochemical factors of water and sediments, macrophytes, macroalgae and benthic macroinvertebrates were monitored in three different periods: (a) every 2 weeks from January 1993 to December 1994 and then monthly until September 1995 at three different study areas established along the spatial gradient described for the south arm of the Mondego estuary (Fig. 1A-C); (b) monthly from January 1996 to January 1997; (c) from December 1998 to December 2005 only in areas $\mathrm{A}$ and $\mathrm{C}$. The units of primary producers and macroinvertebrate biomass were expressed in grams (ash free dry weight, AFDW) per square meters. The counts of feeding wading birds were carried out fortnightly, in low and high tides, from October 1993 to May 1995 (Múrias et al., 1997; Cabral et al., 1999) and monthly from January 1996 to June 2002 only during the low tides (Lopes et al., 2002, 2005). Several studies in Mondego estuary suggested that these trophic levels used into the model construction have characteristics that justify their relevance as ecological indicators: (1) they usually occur in high densities/biomass in the studied areas, (2) they provide cheap and easy measurements if standard methodologies are applied, 
(3) they are sensitive to environmental changes, (4) several species were studied intensively with regard to their natural variation, (5) for many species, demography, behaviour, distribution and phenology are connected with seasonal and spatial changes through gradients of estuarine eutrophication, and (6) they have the capacity for population recovery in response to good management procedures (Cabral et al., 2001; Kamer et al., 2001; Cardoso et al., 2002, 2004a; Lopes et al., 2002; Marques et al., 2002; Dolbeth et al., 2003).

\subsection{Statistical analysis and modelling procedures}

A stepwise multiple regression analysis (Zar, 1996) was used to test relationships between biological metrics and the environmental variables. The dependent variables, selected as representative of the estuarine trophic chain, were: (a) the total biomass of the green macroalgae, (b) the biomass of Z. noltii, (c) the biomass of two key-species of the macroinvertebrate community (H. ulvae and C. carinata) and (d) the number of species and number of individuals of feeding waders. From a bottom up perspective, each living component interacts with other living components (e.g., competition and predation interactions) and non-living features of their shared habitat. A step down procedure was used to test the effect of each variable in the presence of all other pertinent variables, with the least significant variable being removed at every step. The analysis stopped when all the remaining variables had a significant level $P<0.05$ (Zar, 1996). This procedure gives realism to the trophic interactions considered by incorporating into the model a typical "cascade effect" observed in the dynamic of these communities (Cabral et al., 1999; Dolbeth et al., 2003, 2005; Ferreira et al., 2004; SilvaSantos et al., 2006). In fact, nutrient-stimulated macroalgal mats may determine severe effects on macrophyte-dominated systems. For instance on the success of predaceous macroinvertebrate feeding on infaunal communities, the efficiency of shorebirds seeking prey on marsh mudflats, and many others upwardly cascading effects (Cabral et al., 1999; Lopes et al., 2000; Valiela et al., 2004). Therefore, in order to simplify the model structure, only the main trophic key-components were introduced as representative ecological indicators, but which obviously could be complemented by other relevant state variables or other dynamic variables in further applications. The specifications of all variables considered are indicated in Table 1. Although the lack of normality distribution of the dependent variables was not solved by any transformation (Kolmogorov-Smirnov test), the linearity and the homoscedasticity of the residuals were achieved by using logarithmic transformations $\left(X^{\prime}=\log [X+1]\right)$ in each side of the equation, i.e., on both the dependent and independent variables (Zar, 1996; Podani, 2000). The lack of substantial intercorrelation among independent variables was confirmed by the inspection of the respective tolerance values. All the statistical analysis was carried out using the software SYSTAT $8.0^{\circledR}$. Since this statistical procedure was based on a database, resulting from long-term monitoring of Mondego estuary, that include true gradients of environmental and biological characteristics, over space and time, the significant partial regression coefficients were assumed as relevant holistic ecological parameters in the dynamic model construction.

\begin{tabular}{|c|c|c|}
\hline Variables & Specification & Code \\
\hline \multicolumn{3}{|l|}{ Independent variables } \\
\hline Ammonia-N & $\mathrm{mg} \mathrm{L}^{-1} \mathrm{NH}_{4}^{+}$ & $\mathrm{NH} 4$ \\
\hline Dissolved oxygen & $\mathrm{mgL}^{-1}$ & $\mathrm{O} 2$ \\
\hline Medium substrate grain size & $\mathrm{mm}$ & SUB \\
\hline $\begin{array}{l}\text { Monthly cumulative } \\
\text { precipitation }\end{array}$ & $\mathrm{mm}$ & CPREC \\
\hline Nitrates & $\mathrm{mgL}^{-1} \mathrm{~N}$ & NTA \\
\hline Nitrites & $\mathrm{mgL}^{-1} \mathrm{~N}$ & NTI \\
\hline Organic matter & $\%$ & $\mathrm{OM}$ \\
\hline $\mathrm{pH}$ & $\mathrm{pH}$ units & $\mathrm{pH}$ \\
\hline Phosphorous & $\mathrm{mgL}^{-1} \mathrm{P}$ & $\mathrm{P}$ \\
\hline Photoperiod & $\min$ & PHOTPER \\
\hline Salinity & $g L^{-1}$ & SALIN \\
\hline Silica & $\mathrm{mgL}^{-1} \mathrm{Si}$ & SILIC \\
\hline Water residence time & $\mathrm{h}$ & TIMERES \\
\hline Water temperature & ${ }^{\circ} \mathrm{C}$ & TEMP \\
\hline \multicolumn{3}{|l|}{ Dependent variables } \\
\hline $\begin{array}{l}\text { Biomass of total green } \\
\text { macroalgae }\end{array}$ & $\mathrm{g} \mathrm{m}^{-2} \mathrm{AFDW}$ & TGM \\
\hline Biomass of Zostera noltii & $\mathrm{g} \mathrm{m}^{-2} \mathrm{AFDW}$ & ZOST \\
\hline Biomass of Hydrobia ulvae & $\mathrm{g} \mathrm{m}^{-2} \mathrm{AFDW}$ & HYD \\
\hline Biomass of Cyathura carinata & $\mathrm{g} \mathrm{m}^{-2} \mathrm{AFDW}$ & CYAT \\
\hline Total number of birds & No. of individuals & TBIRD \\
\hline Number of birds species & No. of species & SPBIRD \\
\hline
\end{tabular}

This is the heart of the philosophy of the StDM. In a holistic perspective, the partial regression coefficients represent the global influence of the environmental and trophic variables selected, which are of significant importance on several complex ecological processes. Yet, the latter were not included explicitly in the model, but were related to the state variables under consideration. Such procedure was based on data from January 1993 to September 1995 at the three study areas and June 2000 to December 2005 only in areas A and C (Fig. 1), excepting wading birds counts carried out fortnightly from October 1993 to May 1995 and June 2000 to June 2002 along the entire south arm. To develop the dynamic model we used STELLA 8.1.1 ${ }^{\circledR}$.

For validation purposes, biological and physicochemical data, from two independent periods, from January 1996 to January 1997 and from February 1999 to April 2000, were used to confront the simulated values of a given state variable with the real values of the same component. A regression analysis (MODEL II) was performed to compare the observed real values of the selected trophic components with the expected values obtained by model simulations for the same periods. At the end of each analysis, the $95 \%$ confidence limits for the intercept and the slope of the regression line were determined which, together with the results of the respective analysis of variance (ANOVA), allowed to assess the proximity of the simulations produced with the observed values (Sokal and Rohlf, 1995). When the results of the regression analysis were statistically significant, i.e., when the intercept of the regression line was not statistically different from 0 and the slope was not statistically different from 1 , the model simulations were considered validated (Sokal and Rohlf, 1995; Oberdorf et al., 2001). When the validation procedure was not possible (e.g., observations with non-variable values, such as the value $0 \mathrm{~g} \mathrm{~m}^{-2}$ 
of $Z$. noltii biomass in area $C$ ), the percentage of coincidence between simulated and observed points was calculated. For the same state variables and study period, the progress of the simulations performance were evaluated by comparing the MODEL II regression analysis results between the two model versions, the present version and the version from our previous work (Silva-Santos et al., 2006).

After the validation procedures, the trends of each selected state variable were simulated facing real scenarios of environmental management in the Mondego estuary. These simulations were based on stochastic principles taking into consideration the random behaviour of some environmental variables with influence on the studied ecological phenomena. The limit values of environmental variables were determined, from the period between January 1993 and February 2006, to discriminate the maximum and minimum values of each stochastic environmental variable, included in the model as a RANDOM function (Appendix A, other functions). Thus, the model is prepared to work with table functions for validation purposes (Validation Mode) and to produce stochastic simulations based on the monthly stochastic variability of each environmental variable (Random Mode). The selection of the model working mode is done by switching the toggle option between 0 and 1 for validation or stochastic calculations, respectively.

The stochastic scenario considered, for academic demonstration purposes, was based on a possible temporal succession of environmental conditions in the Mondego estuary as result of the mitigation measures implemented since 1998 (described in Section 1). These measures aimed to control the anomalous nutrient enrichment of the south arm, allowing the recovery of the seagrass ( $\mathrm{Z}$. noltii) biomass. The notable reduction of the ammonia concentration in water column and the gradual recovery of the seagrass meadows are the most important consequences of such measures (Lilleb $\varnothing$ et al., 2005). Therefore, the real data for ammonia concentrations and $Z$. noltii biomass were plotted for the periods before (1993-1997) and after (1998-2002) the implementation of the mitigation measures in order to calculate their decreasing and increasing rates, respectively. The slope of the respective regression lines was assumed as the temporal rate for each trend. The following two steps of estuarine environmental changes were adopted through a simulation period of 12 years: (1) the progressive eutrophication of the Mondego estuary occurs in the first 4 years due to the high values of nutrient loading, and, when the mitigation option is activated (Appendix A, other functions); (2) the implementation of mitigation measures, which allow a gradual water quality recovery, is simulated during the last 8 years. For the step 2, the results of the management actions (similar to those recorded since 1998) were simulated, particularly regarding the progressive decrease of ammonia concentration in water. The rate of this trend was introduced into the model as a RAMP function (Appendix A, other functions). The stochastic simulations were determined by RANDOM functions, with a monthly variation, taking into account the maximum and minimum limits for each environmental variable considered (Appendix A, other functions). For graphical representations, 10 stochastic simulations were carried out for the simulation period and the average tendencies were calculated for all the six state variables considered in this study.

\section{Results and discussion \\ 3.1. Determining the cause-effect relationships between trophic components}

In the StDM, a stepwise multiple-regression analysis was used to search for significant correlations between biological and environmental variables of the three areas used in the model construction. The datasets used for upgrading the model construction were substantially increased when compared with our initial version (Silva-Santos et al., 2006). In fact, the new data from 1998 to 2005 gives more robustness and realism to the calculations of the significant relationships between the selected trophic components. The first trophic level (primary producers) was affected by several physicochemical parameters (Table 2). Significant negative correlations were also detected between Z. noltii (ZOST) and Total Green Macroalgae (TGM) biomass, which revealed either different spatial habitat occurrences or some degree of competition between these two autotrophic components. Physicochemical and primary producers' biomass seemed to be the main influencing factors on the second trophic level biomass tendencies represented by H. ulvae (HYD) and C. carinata (CYAT) (Table 2). The upper trophic level, represented by the number of wading bird species (SPBIRD) and total abundance of wading bird individuals (TBIRD) was influenced by the preceding levels, concretely by $H$. ulvae and $Z$. noltii biomass for SPBIRD and total of green macroalgae biomass for TBIRD (Table 2). In fact, some studies reveal $\mathrm{H}$. ulvae as an important prey item in waders' diet (e.g. Raffaelli and Milne, 1987; Múrias et al., 2002). The negative influence of green macroalgae biomass on the abundance of feeding wading birds (TBIRD) corroborates other conventional studies in the Mondego estuary that have come to similar results (e.g. Cabral et al., 1999; Lopes et al., 2006; Múrias et al., 1996, 2005). Photoperiod is a well-known factor that determines wader migrations and naturally appears in our model negatively related with SPBIRD and TBIRD. All the biological and physicochemical significant influences are expressed in Table 2.

\subsection{Conceptualisation of the model and equations}

The diagram of the model presented in Fig. 2 is based on the relationships detected in multiple regression analysis (Table 2) and on existing relevant regional data sets. Therefore, the model includes the following six state variables: two related to the primary producers biomass, two related to the macroinvertebrate biomass and two related to the wading bird number of individuals and species, respectively (Fig. 2). Since difference equations that describe the processes affecting the state variables are expressed in a logarithm of the biological variables (Appendix A, state variable equations), the initial values of all state variables, indicated in Appendix A (process equations), are expressed in a logarithm of the respective units. Later, for validation purposes, the initial value (January 1996 and February 1999) was discarded, since only in t1 (first point 
Table 2 - The regression equations for dry (D) and rainy (R) months, degrees of freedom (d.f.), coefficient of determination $\left(R^{2}\right), F$-value and their significance level $\left({ }^{* * *} P<0.001\right)$ for all the variables combination selected as significant by stepwise multiple regression

\begin{tabular}{|c|c|c|c|c|}
\hline Equations & D or W months & d.f. & $R^{2}$ & F \\
\hline $\begin{array}{l}\log \text { TGM }=-15.646+2.911(\log \text { PHOTPER })-0.410(\log \text { TIMERES }) \\
\quad+0.894(\log \text { O2 })+7.155(\log \mathrm{pH})-3.292(\log \mathrm{NTA})+1.740(\log \mathrm{NH} 4) \\
\quad+0.855(\log \mathrm{OM})-0.252(\log \mathrm{ZOST})\end{array}$ & $\mathrm{D}$ & 170 & 0.362 & $12.079^{*+1+}$ \\
\hline $\begin{array}{l}\log \mathrm{TGM}=-15.443+0.567(\log \text { CPREC })+4.957(\log \text { PHOTPER }) \\
\quad+0.885(\log \text { OM })-0.185(\log Z O S T)\end{array}$ & W & 73 & 0.403 & $12.307^{+*+1}$ \\
\hline $\begin{array}{l}\log \text { ZOST }=-6.658-19.424(\log \text { SUB })+7.451(\log p H)- \\
1.949(\log N H 4)+1.998(\log \text { OM })-0.482(\log \text { TGM })\end{array}$ & $\mathrm{D}$ & 173 & 0.406 & $23.666^{*+1+}$ \\
\hline $\begin{array}{l}\log \text { ZOST }=-12.902-31.048(\log \text { SUB })+16.003(\log p H)- \\
27.152(\log \text { NTI })-0.538(\log \text { TGM })\end{array}$ & W & 73 & 0.443 & $14.511^{*+1+}$ \\
\hline $\begin{array}{l}\log \text { HYD }=-0.372+0.961(\log \text { TEMP })-9.474(\log \text { SUB }) \\
\quad+27.944(\log N T I)+0.132(\log \text { TGM })+0.436(\log Z O S T)\end{array}$ & $\mathrm{D}$ & 172 & 0.536 & $39.739^{*+1+}$ \\
\hline $\log \mathrm{HYD}=-0.242+1.240(\log \mathrm{OM})+0.399(\log \mathrm{ZOST})$ & W & 75 & 0.627 & $63.150^{+*+1}$ \\
\hline $\begin{array}{l}\log \text { CYAT }=0.678+17.783(\log \text { SUB })-0.475(\log \text { TIMERES }) \\
\quad+4.119(\log P)-7.700(\log \text { NTI })+0.581(\log \text { SILIC })-0.709(\log \text { OM })\end{array}$ & $\mathrm{D}$ & 127 & 0.794 & $81.391^{+*+1}$ \\
\hline $\begin{array}{l}\log \text { CYAT }=-0.524-0.207(\log \text { CPREC })+17.561(\operatorname{LogSUB})+0.656(\log 02)- \\
0.246(\log \text { SALIN })+0.095(\log \text { TGM })\end{array}$ & W & 52 & 0.800 & $41.563^{*+1+}$ \\
\hline $\log$ SPBIRD $=4.073+0.070(\log Z O S T)-0.140(\log H Y D)-1.036(\log$ PHOTPER $)$ & - & 79 & 0.317 & $12.199^{*+1+}$ \\
\hline $\log$ TBIRD $=15.008-0.248(\log$ TGM $)-4.201(\log$ PHOTPER $)$ & - & 80 & 0.554 & $49.621^{*+1+}$ \\
\hline
\end{tabular}

of the simulation) it was possible to take into account the influences of the environmental variables, whose seasonal fluctuations were introduced into the model as table functions (Appendix A, table functions). Since primary production and associated benthic fauna largely depends on weather conditions (especially precipitation) (Martins et al., 2001; Cardoso et al., 2005; Verdelhos et al., 2005) two different complementary equations were calculated for each one of these components depending on the month categories, i.e., if dry or wet months. This categorization was determined by comparing monthly cumulative precipitations with the reference historical values of monthly precipitation obtained from the period between 1961 and 1990 (Portuguese Weather Institute, http://web.meteo.pt/pt/clima/clima.jsp).

Consequently, the simulation performance of a given state variable results from the calculations of two alternative equations automatically selected in response to the monthly precipitation influence (Fig. 2, Table 2 and Appendix A, state variable equations). The inflows affecting the ecological state variables were based on the positive constants and all positive partial coefficients of each variable resulting from the previous multiple regression analysis (Fig. 2, Table 2 and Appendix $\mathrm{A}$, state variable and process equations). Total green macroalgae, $Z$. noltii, $H$. ulvae and $C$. carinata biomass were affected by two inflows corresponding to the conditions of dry or wet months (TGM gains Dry, TGM gains Wet, ZOST gains Dry, ZOST gains Wet, HYD gains Dry, HYD gains Wet, CYAT gains Dry, CYAT gains Wet). Using the same criteria, each one of these state variables was affected by two outflows related to the negative constants and partial regression coefficients (Fig. 2, Table 2 and Appendix A, state variable and process equations) (TGM losses Dry, TGM losses Wet, ZOST losses Dry, ZOST losses Wet, CYAT losses Dry, CYAT losses Wet). The rate of the biological decay of $Z$. noltii biomass, observed before the implementation of the mitigation measures, was assumed as an outflow in the respective state variable using a RAMP function controlled automatically by the physicochemical characteristics related with the water eutrophic status (in this case by the values of ammonia concentrations in water column) (Fig. 2 and Appendix A, other functions). As shown previously (Raffaelli et al., 1989; Múrias et al., 1996), changes in numbers of feeding wading birds in response to short-term variations of local eutrophication and weather conditions occurs in the medium to long-term, thus proceeding in parallel with the slow changes in the densities and structure of the prey populations. Viewed in this light, the two state variables related with waders were affected only by an inflow and an outflow (SPBIRD gains vs. SPBIRD losses and TBIRD gains vs. TBIRD losses, respectively) without the alternative switch in response to the "instantaneous" effect of precipitation. Although biomass output for each metric in our StDM model simulation is composed of a given value per time unit, the respective state variable might have a cumulating behaviour over time in response to environmental condition changes. Therefore, to prevent this from happening, six outflow adjustments were incorporated in the model (TGM adjust, ZOST adjust, HYD adjust, CYAT adjust, SPBIRD adjust and TBIRD adjust) aiming to empty the state variables at each time step, by a "flushing cistern mechanism", before beginning the next step with new environmental influences (Fig. 2 and Appendix A, state variable and process equations). For process compatibilities and a more realistic comprehension of the model simulations, some conversions were introduced, denominated associated variables (Fig. 2 and Appendix A, associated variables). Regarding biological variables, these conversions were obtained through an inverse transformation (anti-logarithmic), which transforms logarithms into the original measurement units (TGM, ZOST, HYD, CYAT, SPBIRD and TBIRD). The physicochemical variables were logarithm transformed for a compatible integration in the balances of the state 


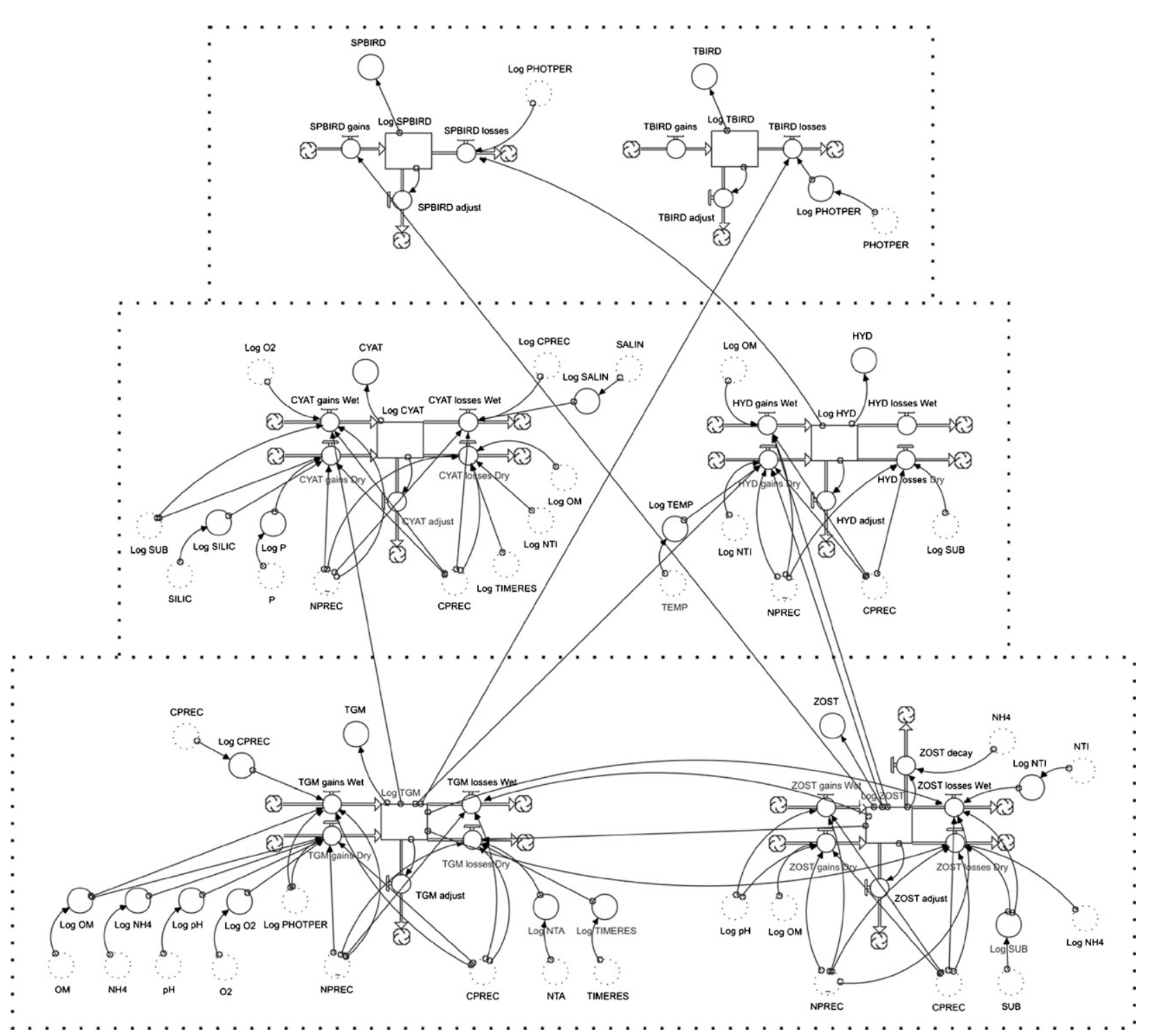

Fig. 2 - Conceptual diagram of the model used to predict the trophic drifts produced by gradients of changes of the environmental variables from the studied areas in the south arm of the Mondego estuary. The pyramidal boxes represent the trophic "cascade effect". The specification of all variable codes is expressed in Table 1.

variables (Fig. 2 and Appendix A, associated variables). This transformation was incorporated because the data required for the state variables balances should have the same units used to obtain the partial regression coefficients, assumed as holistic ecological parameters (see Section 2). Therefore, only logarithms of the physicochemical variables are acceptable in the inflows and outflows of the state variables (Fig. 2, Table 2 and Appendix A, state variable and process equations) being the model prepared for receiving and transforming real data from the environmental variables and to convert logarithmic outputs from state variables simulations into original units. Medium substrate grain size (SUB) in each sampling area was assumed as static, without any variation during the simulated period, and, therefore, were introduced as environmental constant (Appendix A, constants). The water residence time (TIMERES-time needed to renovate $90 \%$ of a certain ini- tial volume of water) of the south arm is influenced both by precipitation and by water discharges from the Pranto river depending on the water needs in rice fields of the Mondego Valley. Neto (2004) estimated the water residence time (TIMERES) for three different levels of sluice discharges from the Pranto river: minimum discharge (MinTIMERES, $52.8 \mathrm{~h}$ for area $\mathrm{A}$ and $146 \mathrm{~h}$ for area $\mathrm{C}$ ), intermediate discharge (IntTIMERES, $26.4 \mathrm{~h}$ for area $\mathrm{A}$ and $30 \mathrm{~h}$ for area $\mathrm{C}$ ) and maximum discharge (MaxTIMERES, 19.2 h for area A and $20 \mathrm{~h}$ for area C). For simulations purposes, these values of water residence time were automatically generated taking into account the precipitation values and the agricultural calendar (Fig. 3 and Appendix A, other functions). When the monthly cumulative precipitations exceed the respective historical value, the model assumes the lower water residence time for each area. 


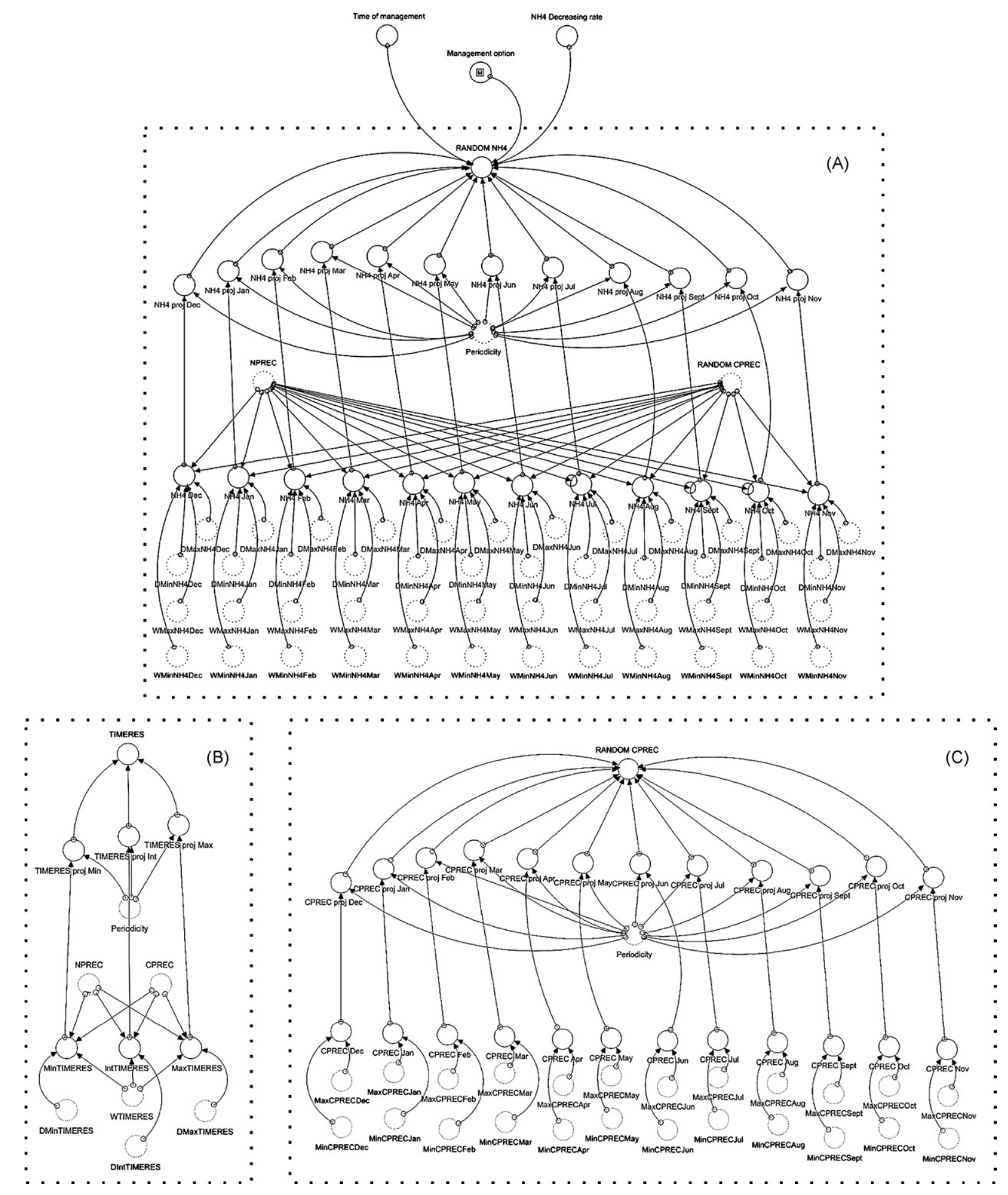

Fig. 3 - Conceptual diagrams of the sub-models used to generate monthly stochastic calculations from the environmental and hydraulic data incorporated into the model: (A) the standard diagram used for all the sub-models of physicochemical stochastic influences (NH4, O2, NTA, NTI, OM, pH, P, SALIN, SILIC and TEMP). For illustration purposes, the diagram for the NH4 sub-model is shown as an example; (B) the diagram used for TIMERES calculations; (C) the diagram used for monthly CPREC stochastic simulations. The specification of these variable codes is expressed in Table 1. 


\subsection{Model simulations}

The temporal unit chosen was the month, because it captures in an acceptable way the average ecological variations that occur in the Mondego estuary. Simulations were performed in two different periods: from January 1996 to January 1997 and from February 1999 to April 2000. Since the values of the first month for each period were used as initial values $\left(t_{0}\right)$, the simulations started effectively in February 1996 and March 1999.

Fig. 4 illustrates the confrontation between simulated and the real values for all the biological variables under consideration. The data sets from the sampling campaigns carried out in the last years allowed us to compare values for primary pro- ducers in areas A and C, for benthic macroinvertebrates (only in area $C$ ) and for wading birds in the whole south arm of Mondego estuary. The model predicts with success four of the eight simulations performed. In fact, the behaviour of the total green macroalgae (TGM) and Z. noltii (ZOST) biomass in area $A$, the number of bird species (SPBIRD) and the total number of birds (TBIRD) in the entire south arm (Fig. 4) were statistically validated by the MODEL II regression analysis (Table 3). Despite the non-significant results for the remain simulations, we could easily recognize logic behavioural patterns for total green macroalgae biomass (TGM) and H. ulvae biomass in area C (Fig. 4 and Table 3) and a seasonal stable pattern for C. carinata biomass (Fig. 4) consistent with the observed on populations at the south of Europe (Bamber, 1985; Sola and
TGM A

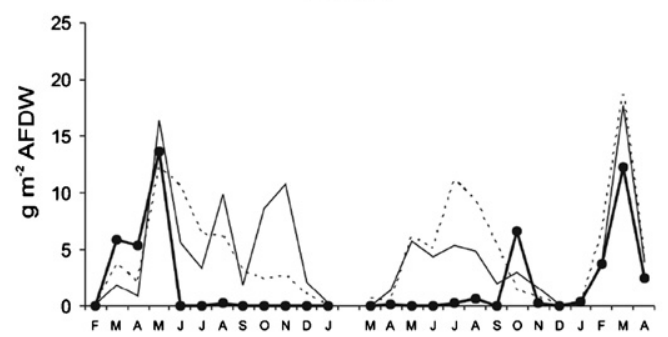

TGM C

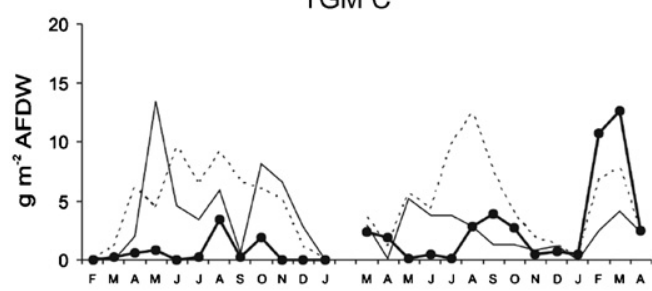

HYD C

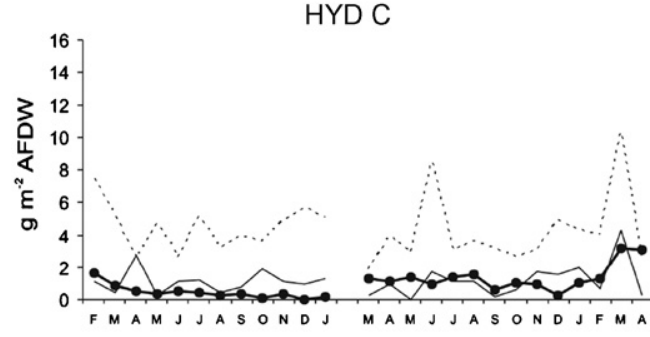

SPBIRD South arm

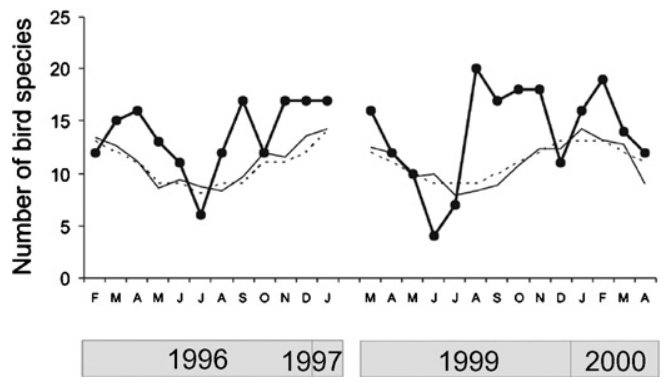

ZOST A

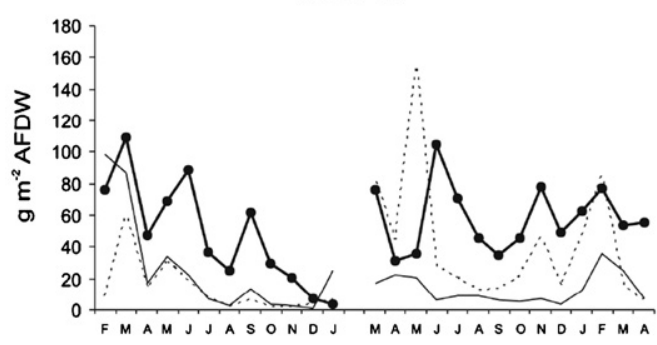

ZOST C

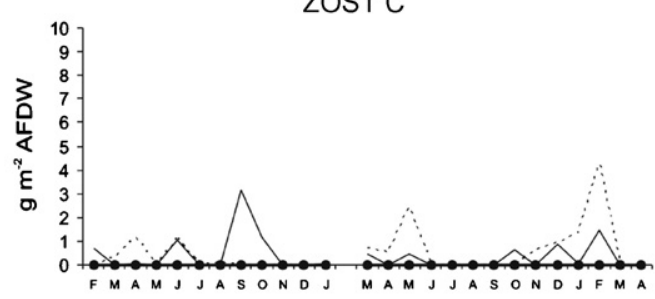

CYAT C

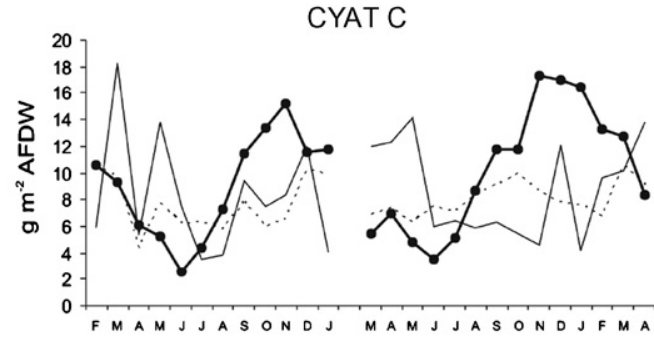

TBIRD South arm

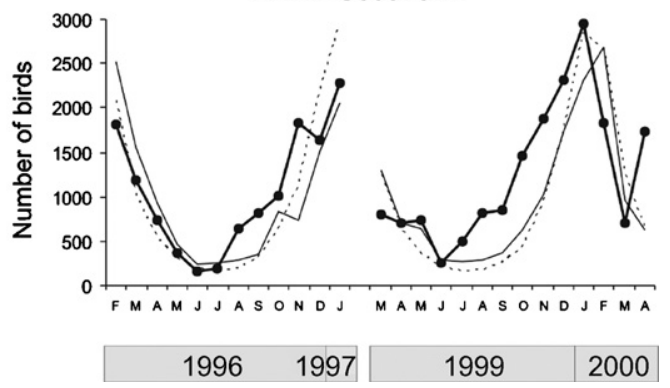

Fig. 4 - Graphical comparisons between simulations obtained in our previous work Silva-Santos et al. (2006) (dashed line), simulations obtained in the present work (solid line) and observed values (solid line with dots) of the biological variables TGM, ZOST, HYD, CYAT, TBIRD and SPBIRD. A and C are the two sampling areas, from which the available data is used for validation purposes. The specification of these variable codes is expressed in Table 1. 
Table 3 - Regression analysis (MODEL II) results: intercepts, slopes and respective 95\% confidence limits (in parentheses), degrees of freedom (d.f.), coefficient of determination $\left(R^{2}\right), F$-value and their significance level $\left(P<0.05 ;{ }^{* * *} P<0.001\right)$ for all the observed vs. expected values of the biological variables considered

\begin{tabular}{|c|c|c|c|c|c|c|}
\hline Metrics & Station & Intercept & Slope & d.f. & $R^{2}$ & $F$ \\
\hline TGM & A & $-1.10(-3.23$ to 0.37$)$ & $0.70(0.37-1.17)$ & 25 & 0.3772 & $14.534^{* * *}$ \\
\hline TGM & $\mathrm{C}$ & $-4.51(0.88-10.13)$ & $2.09(-2.68$ to 0.33$)$ & 25 & 0.0019 & 0.045 (n.s.) \\
\hline ZOST & A & $27.66(-23.62$ to 42.14$)$ & $1.35(0.60-4.00)$ & 25 & 0.2167 & $6.638^{*}$ \\
\hline HYD & $\mathrm{C}$ & $0.34(-4.70$ to 1.42$)$ & $0.53(-0.41$ to 4.93$)$ & 25 & 0.0492 & 1.241 (n.s.) \\
\hline CYAT & C & $28.95(-5.27$ to 11.54$)$ & $-2.25(-0.22$ to 1.75$)$ & 25 & 0.0111 & 0.271 (n.s.) \\
\hline TBIRD & Entire south arm & $194.48(-227.62$ to 489.79$)$ & $0.98(0.68-1.41)$ & 25 & 0.5858 & $33.945^{* * *}$ \\
\hline SPBIRD & Entire south arm & $-32.15(-1634.70$ to -8.20$)$ & 4.16 (1.99-149.19) & 25 & 0.1508 & $4.261^{*}$ \\
\hline
\end{tabular}

Without management

ZOST A

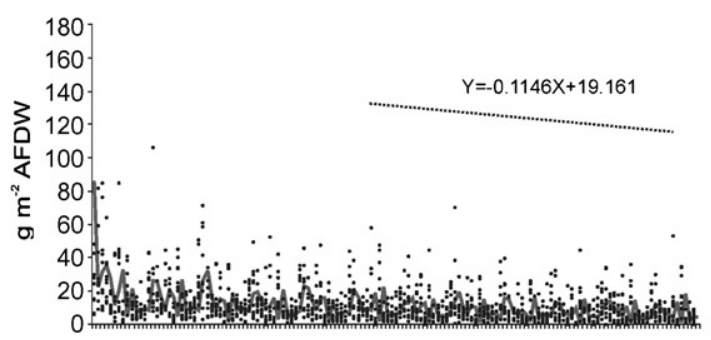

TGM A

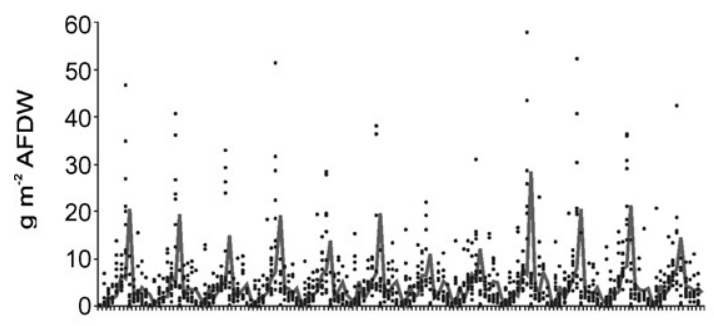

ZOST C

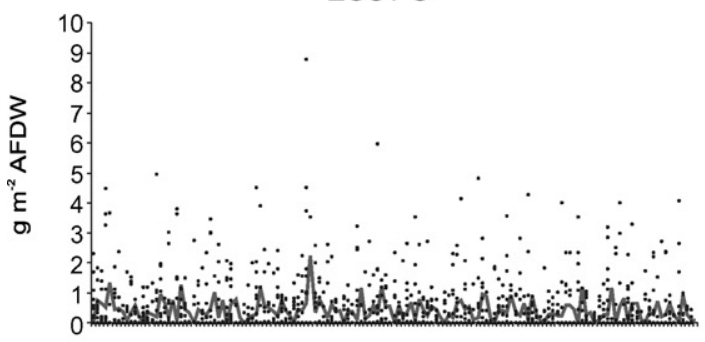

TGM C

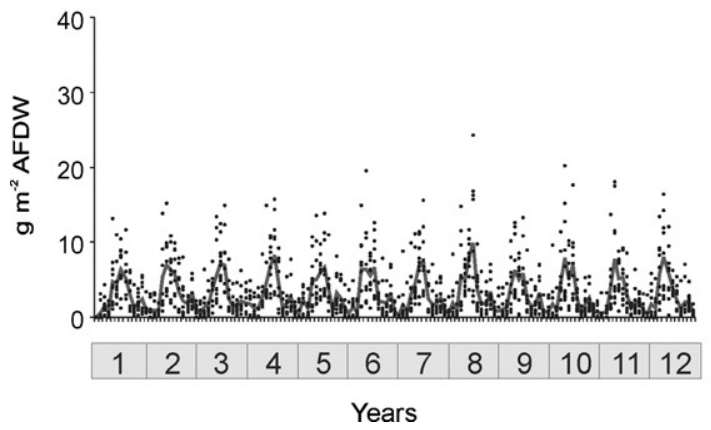

With management

ZOST A

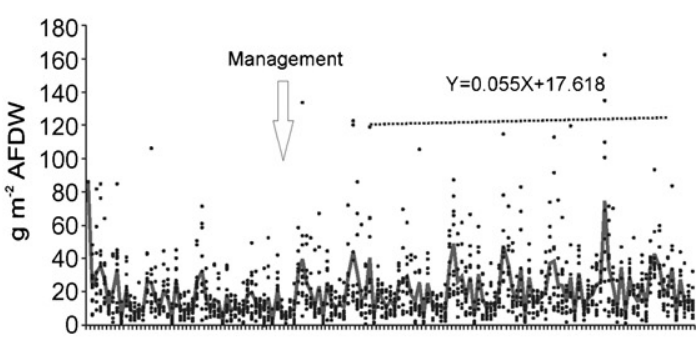

TGM A
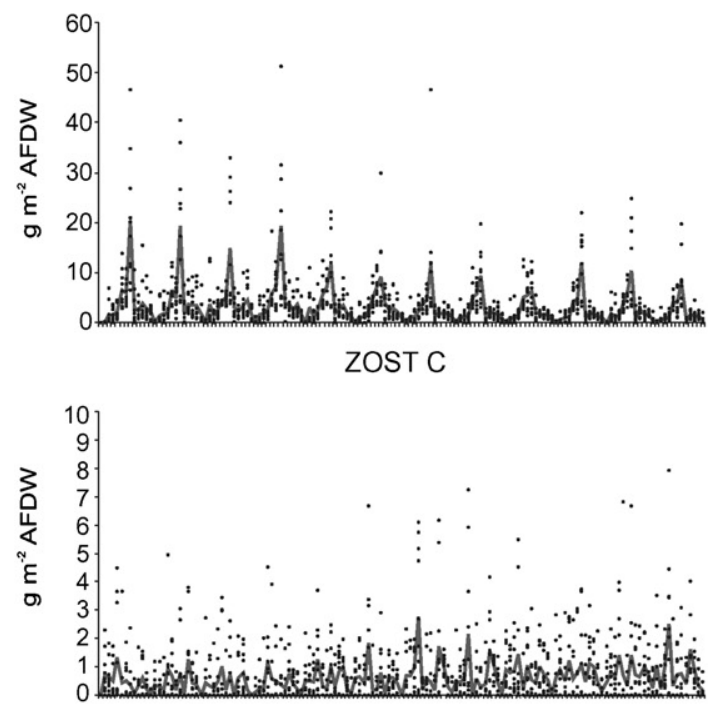

TGM C

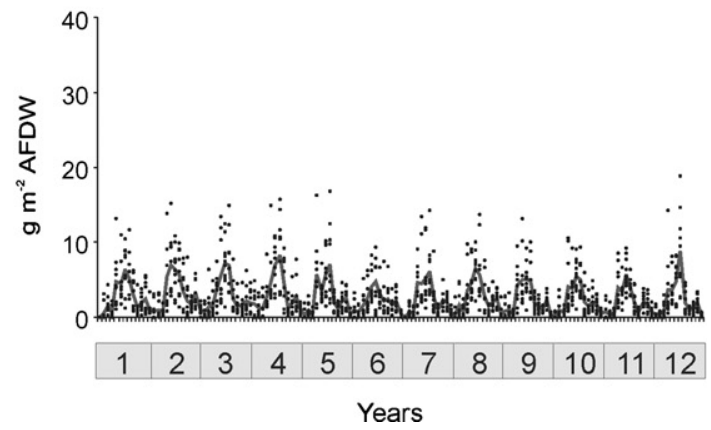

Fig. 5 - Computer simulations for the biological variables estimated responses with and without the implementation of management practices (through a period of 12 years). The line connects the average values of monthly simulations. 
Without management

HYD C

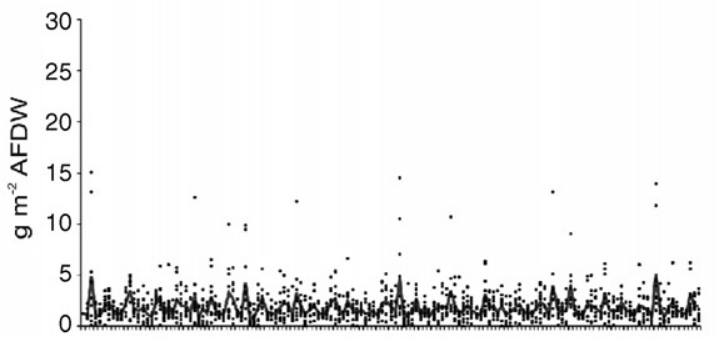

CYAT C

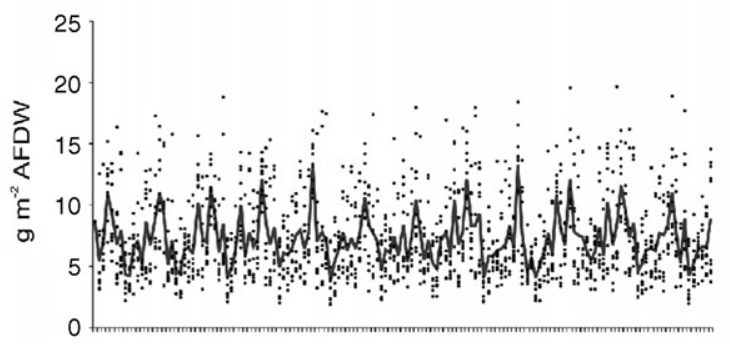

SPBIRD South arm

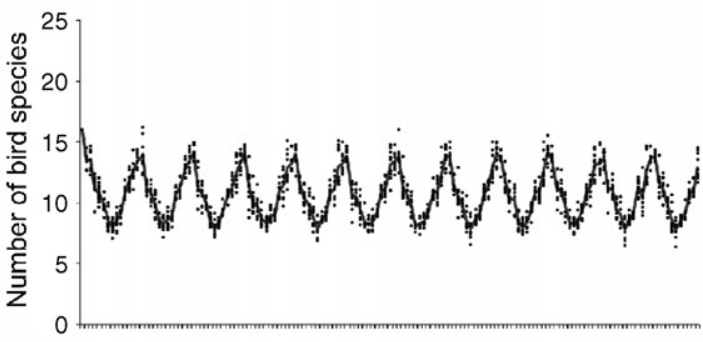

TBIRD South arm

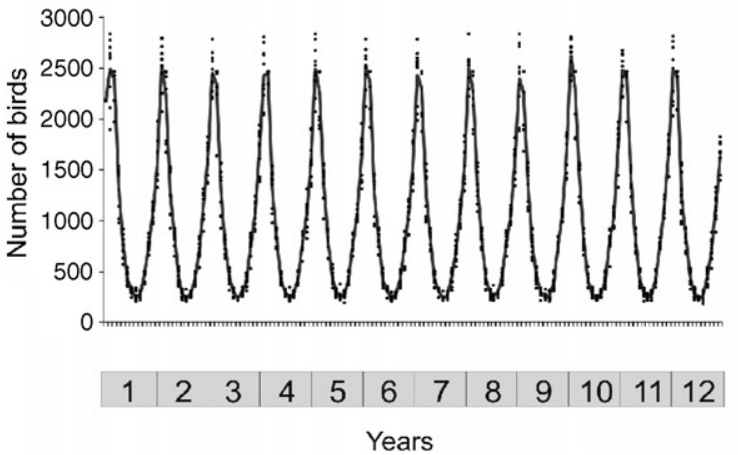

With management

HYD C

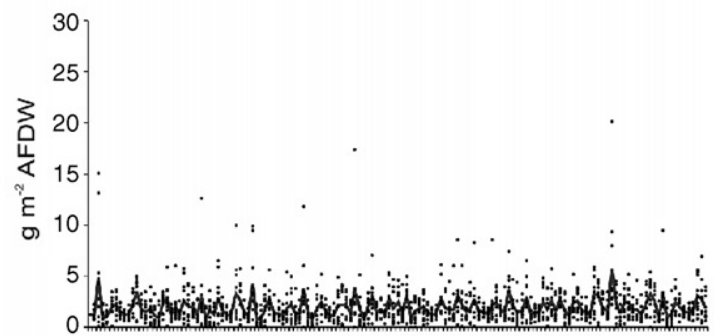

CYAT C

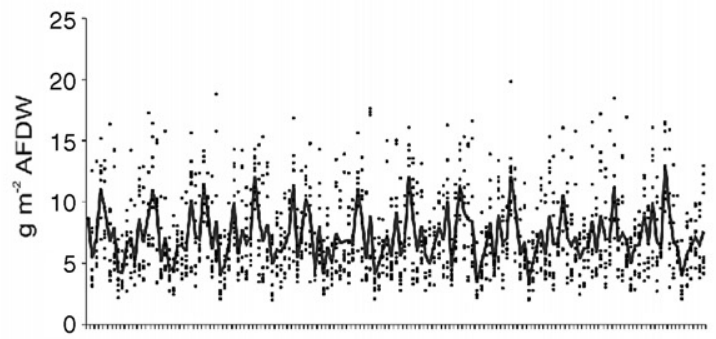

SPBIRD South arm

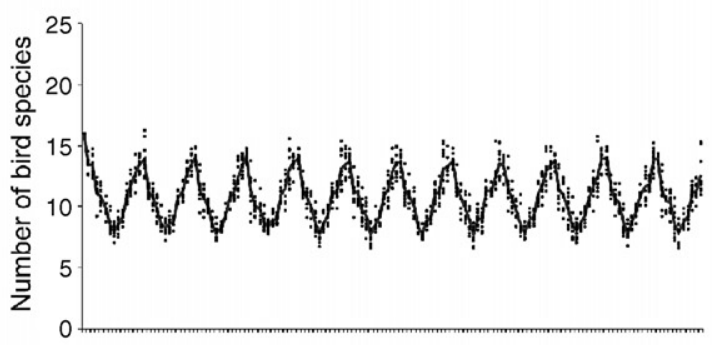

TBIRD South arm

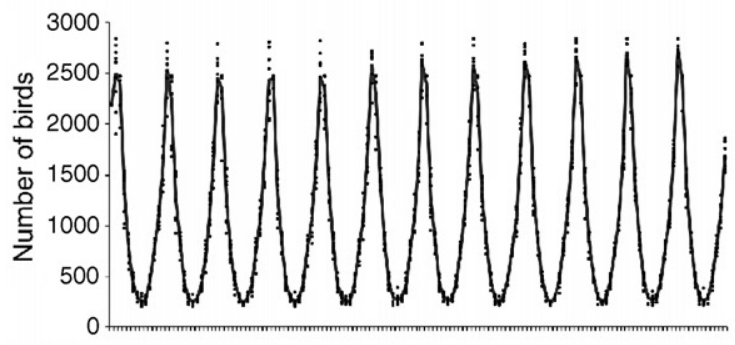

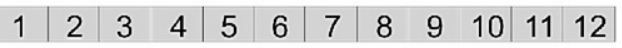

Years

Fig. 5 - (Continued).

Arzubialde, 1993; Marques et al., 1994; Ferreira et al., 2004). Since it was not possible validated the simulations produced for Z. noltii biomass (ZOST) in area C, the performance was empirically assessed by the inspection of the degree of coincidence between simulated and observed values. From a total of 26 points (months) simulated, 19 were coincident with real data, which represents $73.1 \%$ of coincidence. Moreover, $23.1 \%$
(6 points) and 3.8\% (1 point) of the simulated points for $Z$. noltii biomass (ZOST) in area $C$ represents very small deviations from the real values $\left(0 \mathrm{~g} \mathrm{~m}^{-2}\right), 1 \mathrm{~g} \mathrm{~m}^{-2}$ and $3 \mathrm{~g} \mathrm{~m}^{-2}$ respectively, which had almost no biological relevance in practical terms. Therefore, the model reacted in a differentiated way between area A, with favourable conditions for $\mathrm{Z}$. noltii occurrence in high biomass values, and area $\mathrm{C}$, where the conditions needed 
for the establishment of a community of $Z$. noltii were deficient (Pardal et al., 2000; Martins et al., 2001) (Fig. 4). Overall, comparing with our previous work (Silva-Santos et al., 2006), for the same validation periods, the performance of the present simulation results shows more realism in capturing either: (1) the behavioural patterns of the state variables, in general with higher statistical significance or degree of coincidence between simulated and observed values; or (2) the mechanisms of underlying ecological "cascade" processes (Fig. 2 and Fig. 4).

The ecological indicators under consideration were monitored for ecosystem health assessments in the south arm of the Mondego estuary, specially focused in the Z. noltii beds (Pardal et al., 2000; Cardoso et al., 2002, 2004b; Ferreira et al., 2004; Dolbeth et al., 2005). In this scope, some mitigation measures were implemented since 1998: (1) the water circulation was partially re-established allowing freshwater inputs from the north arm through overflow episodes favouring nutrients dilution (e.g. ammonia concentrations decrease) and (2) the nutrient loadings were reduced by correcting the inappropriate sluice handling and fertilisers overloading (Lillebø et al., 2005; Verdelhos et al., 2005).

After the validation procedures, StDM simulations (Fig. 5) were used to test the model's performance in area A and C of the south arm, facing the scenarios of mitigation described. The model simulations showed credible trends for $Z$. noltii biomass responses before and after the implementation of the mitigation measures (Fig. 5). In fact, the decrease in ammonia concentrations, a confirmed result from those measures, induces a moderately recover in $\mathrm{Z}$. noltii biomass concomitant with a slowly decrease in macroalgae biomass in area A (Fig. 5), with rates very similar to the real recovery rates described by Lillebø et al. (2005). These simulations are, however, less optimistic than the empiric projections discussed by Neto (2004) suggesting that $Z$. noltii meadows will recover the condition shown in 1993 in 7-8 years after the management actions implemented in the south arm. On the other hand, the scenarios without the implementation of management actions shows a progressively decay of $Z$. noltii biomass (Fig. 5) with a pattern and rate that matching the trends recorded by Lilleb $\varnothing$ et al. (2005) before 1998. Independently to the scenario options, our simulations show that there are no conditions to the establishment of viable Z. noltii beds in area C (Fig. 5), maybe as a consequence of an unpropitious sedimentary dynamics. With regard to the two key-species from the macroinvertebrate benthic community and the specific richness and abundance of waders the trends simulated (Fig. 5) suggests that those groups are relatively resilient to the eutrophication levels recorded in the Mondego estuary and/or that the respective recovery, in response to the implementation of management measures, occurs in the medium to long-term, namely because the recovery rates are normally significantly lower then the degradation rates. Several works confirmed such evidences (Múrias et al., 1996; Beisner et al., 2003; Lillebø et al., 2005; Lopes et al., 2005).

In monitoring and management programs, the construction of predictive tools for ecological management, namely in terms of cost and speed of reliable assessment results, is crucial. Džeroski et al. (1997) referred that models produced in the form of rules, based on machine learning approaches, are transparent and can be easily understood by experts. The StDM exhibits these structural qualities but provides also simple, suitable and intuitive outputs, easily interpreted by non-experts (ranging from resource users to senior policy makers). Although structurally simple, our StDM model captures the stochastic complexity of some holistic ecological trends, including true temporal and spatial gradients of stochastic environmental characteristics, which allowed the simulation of structural changes when habitat and environmental conditions are substantially changing due to anthropogenic-induced alterations.

When compared to other modelling methodologies, such as Artificial Intelligence (Walley and Džeroski, 1995; Džeroski et al., 1997; Walley et al., 1998; Walley and Fontama, 2000; Džeroski et al., 2000; Broekhoven et al., 2006), the StDM is more intuitive, namely in mathematical terms, providing easy explanations for the underlying relations between independent and dependent variables and because is based on conventional linear methods that allowed a more direct development of testable hypotheses (Manel et al., 1999).

Overall, the simulation results reflect well the shift of the environmental characteristics towards known and new expected conditions and the state variables are capable of responding with credibility to key changes, capturing the "trophic cascade" dynamics that typically occur in estuarine ecosystems. As stated in our previous work (Silva-Santos et al., 2006), the StDM model presented in this work is now integrated, as an exploratory tool, in the Mondego estuary management program, allowing the precise simulation of more complicated scenarios, with introduction of new mitigation measures, interactions and interferences (such as land use changes or ecosystems restoration) with precise applicability conditions.

\section{Conclusions}

In the scope of the need for rapid, standardized and cost-saving assessment methodologies (Pardal et al., 2004), the main objective of the StDM approach proposed is a mechanistic understanding of the main holistic ecological dynamics resulting from a complex and variable eutrophication scenario. Our approach includes the interaction between ecological key-components and environmental conditions, with holistic and ecological relevance, from which management strategies can be designed to restore estuarine biological communities that have been damaged by the eutrophication phenomena. This approach also provides a useful starting point, allowing the precise development of more complicated simulation models with the creation of estuarine habitat patterns from changes at the landscape level, whose patterns are the basis of spatially explicit ecological models (Costanza and Voinov, 2003). This new step will include not only the trophic interactions between key-components but also the spatial configuration of the different kinds of natural and seminatural habitats that concur in sustaining the entire ecological integrity of the studied region. Therefore, we believe that StDM will provide the development of more global techniques in the scope of this research area by creating expeditious interfaces with Geographic Information Systems, which will make 
the methodology more instructive and credible to decisionmakers and environmental managers (Costanza, 1992; Santos and Cabral, 2003).

\section{Acknowledgements}

The authors are indebted to all the colleagues from IMARCoimbra who assisted in field and laboratory work. A special thanks is addressed to Dr. João Neto for sharing his residence time data sets from the Mondego estuary.

\section{Appendix A}

Mathematical equations used in STELLA for the trophic relationships between the biological and the environmental variables. As an example, the environmental data of the sampling area C (from January 1996 to January 1997) was used. The specification of all variable codes is expressed in Table 1.

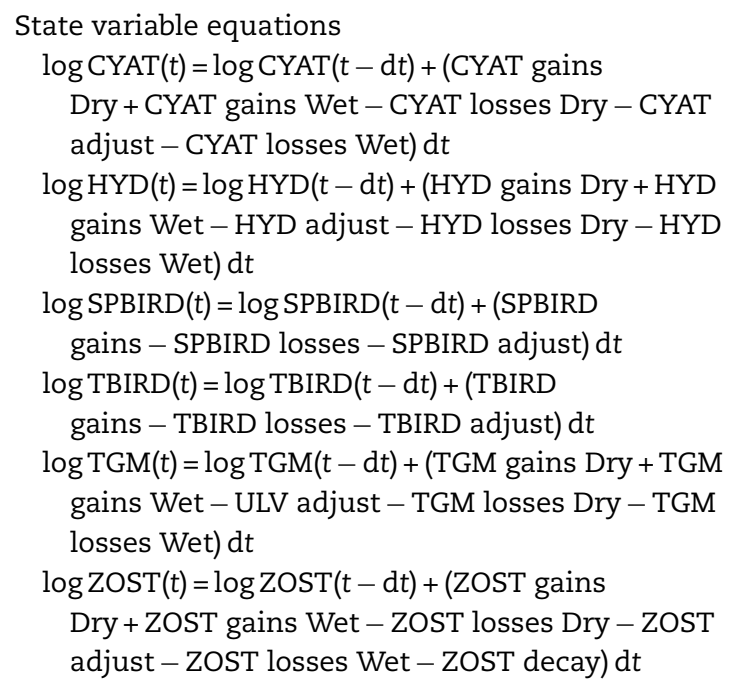

Process equations

(a) $\log$ CYAT

Initial biomass of $\log$ CYAT $=0.9841$

CYAT gains Dry $=$ if CPREC $\leq$ NPREC then

$0.678+17.783 \log$ SUB $+4.119 \log \mathrm{P}+0.581 \log$ SILIC

else 0

CYAT gains Wet $=$ if CPREC $>$ NPREC then

$17.561 \log \mathrm{SUB}+0.656 \log \mathrm{O} 2+0.095 \log \mathrm{TGM}$ else 0

CYAT losses Dry $=$ if CPREC $\leq$ NPREC then

$0.475 \log$ TIMERES + 7.700 log NTI + $0.709 \log$ OM

else 0

CYAT losses Wet $=$ if CPREC $>$ NPREC then $0.524+0.207 \log$ CPREC + 0.246 log SALIN else 0

CYAT adjust $=\log$ CYAT
Appendix A (Continued)

(b) $\log$ HYD

Initial biomass of $\log H Y D=0.3549$

HYD gains Dry $=$ if CPREC $\leq$ NPREC then

$0.961 \log$ TEMP + 27.944 log NTI + 0.132 log TGM

$+0.436 \log$ ZOST else 0

HYD gains Wet $=$ if CPREC $>$ NPREC then

$1.240 \log O M+0.399 \log Z O S T$ else 0

HYD losses Dry $=$ if CPREC $\leq$ NPREC then

$0.372+9.474 \log$ SUB else 0

HYD losses Wet $=0.242$

HYD adjust $=\log$ HYD

(c) $\log$ SPBIRD

Initial richness of $\log$ SPBIRD $=1.2304$

SPBIRD gains $=4.073+0.070 \log \mathrm{ZOST}$

SPBIRD losses $=0.140 \log$ HYD $+1.036 \log$ PHOTPER

SPBIRD adjust $=\log$ SPBIRD

(d) $\log$ TBIRD

Initial richness of $\log$ TBIRD $=3.3397$

TBIRD gains $=15.008$

TBIRD losses $=0.248 \log \mathrm{TGM}+4.201 \log$ PHOTPER

TBIRD adjust $=\log$ TBIRD

(e) $\log$ TGM

Initial biomass of $\log \mathrm{TGM}=0$

TGM gains Dry $=$ if CPREC $<=$ NPREC then

$2.911 \log$ PHOTPER + 0.894 log O2 + 7.155 log pH

$+1.740 \log \mathrm{NH} 4+0.855 \log \mathrm{OM}$ else 0

TGM gains Wet $=$ if $C P R E C>$ NPREC then

$0.567 \log$ CPREC + 4.957 log PHOTPER + $0.885 \log$ OM

else 0

TGM losses Dry $=$ if CPREC $<=$ NPREC then

$15.646+0.410 \log$ TIMERES + 3.292 log NTA + $0.252 \log$ ZOST

else 0

TGM losses Wet = if CPREC $>$ NPREC then

$15.443+0.185 \log$ ZOST else 0

TGM adjust $=\log$ TGM

(f) $\log$ ZOST

Initial biomass of $\log \mathrm{ZOST}=0$

ZOST gains Dry $=$ if CPREC $<=$ NPREC then

$7.451 \log \mathrm{pH}+1.998 \log \mathrm{OM}$ else 0

ZOST gains Wet $=$ if CPREC $>$ NPREC then

$16.003 \log \mathrm{pH}$ else 0

ZOST losses Dry $=$ if CPREC $<=$ NPREC then

$6.658+19.424 \log$ SUB + $1.949 \log \mathrm{NH} 4+0.482 \log \mathrm{TGM}$

else 0

ZOST losses Wet $=$ if CPREC $>$ NPREC then

$12.902+31.048 \log \mathrm{SUB}+27.152 \log \mathrm{NTI}+0.538 \log \mathrm{TGM}$

else 0

ZOST decay $=$ if $\mathrm{NH} 4>0.20$ then

$\log$ ZOST ramp(0.16)/48 else 0

ZOST adjust $=\log Z O S T$ 


\section{Appendix A (Continued)}

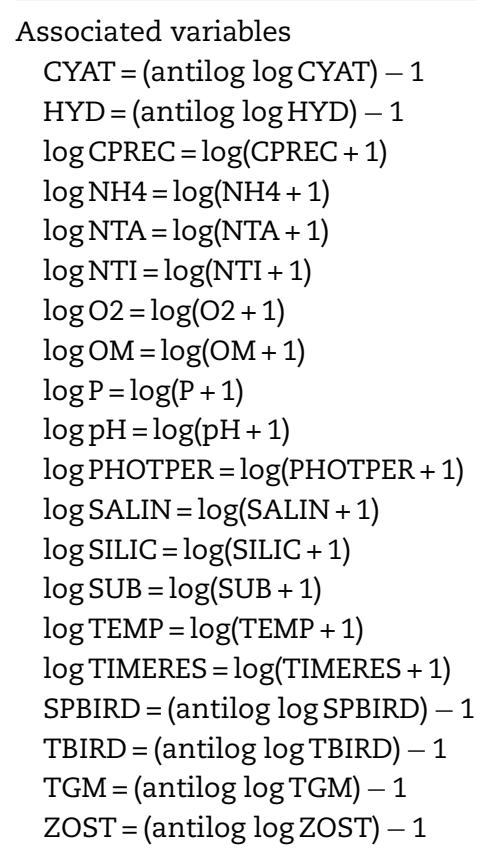

Table functions

MPHOTPER $=$ GRAPH(Periodicity)

(0.00, 562), (1.00, 581), (2.00, 647), (3.00, 733), (4.00, $804),(5.00,872),(6.00,900),(7.00,879),(8.00,817)$, (9.00, 735), (10.0, 666), (11.0, 597)

NPREC $=$ GRAPH $($ month, $\mathrm{mm})$ (0.00, 138), (1.00, 139), (2.00, 88.0), (3.00, 91.0), (4.00, 78.0), (5.00, 51.0), (6.00, 15.0), (7.00, 13.0), (8.00, 47.0), (9.00, 97.0), (10.0, 128), (11.0, 129), $(12.0,138)$ Validation $\mathrm{CPREC}=\mathrm{GRAPH}($ month, $\mathrm{mm})$ (0.00, 336), (1.00, 138), (2.00, 97.9), (3.00, 58.4), (4.00, 141), (5.00, 0.00), (6.00, 0.00), (7.00, 28.0), (8.00, 42.0), (9.00, 3.50), (10.0, 16.1), (11.0, 176), (12.0, 133)

Validation $\mathrm{NH} 4=\mathrm{GRAPH}\left(\mathrm{month}, \mathrm{mgL}^{-1}\right)$ $(0.00,0.767),(1.00,0.301),(2.00,0.268),(3.00$, 0.337), (4.00, 0.0924), (5.00, 0.218), (6.00, 0.282), (7.00, 0.451), (8.00, 0.34), (9.00, 0.423), (10.0, 0.715), (11.0, 0.311), (12.0, 0.602)

Validation NTA $=\mathrm{GRAPH}\left(\right.$ month, $\left.\mathrm{mgL}^{-1}\right)$

(0.00, 1.07), (1.00, 0.612), (2.00, 0.015), (3.00, 0.006), (4.00, 0.064), (5.00, 0.066), (6.00, 0.015), (7.00, 0.003), (8.00, 0.016), (9.00, 0.007), (10.0, 0.047), (11.0, 0.147), (12.0, 0.125)

Validation NTI $=$ GRAPH $\left(\right.$ month, $\left.\mathrm{mgL}^{-1}\right)$ (0.00, 0.0152), (1.00, 0.0329), (2.00, 0.0293), (3.00, 0.0046), (4.00, 0.0137), (5.00, 0.0086), (6.00, 0.0071), (7.00, 0.0053), (8.00, 0.0103), (9.00, 0.0187), (10.0, 0.026), (11.0, 0.0481), (12.0, 0.124)

Validation $\mathrm{O} 2=\mathrm{GRAPH}\left(\right.$ month, $\left.\mathrm{mgL}^{-1}\right)$ $(0.00,10.6),(1.00,11.5),(2.00,12.6),(3.00,13.6)$, (4.00, 14.5), (5.00, 8.90), (6.00, 11.6), (7.00, 16.3), (8.00, 13.0), (9.00, 13.7), (10.0, 13.4), (11.0, 5.50), $(12.0,13.4)$

Validation $\mathrm{OM}=\mathrm{GRAPH}($ month, $\%)$
Appendix A (Continued)

(0.00, 1.90), (1.00, 1.92), (2.00, 3.58), $(3.00,1.62)$, (4.00, 1.85), (5.00, 2.52), (6.00, 2.20), (7.00, 1.45), (8.00, 2.97), (9.00, 3.93), (10.0, 1.86), (11.0, 2.10), (12.0, 3.73)

Validation $\mathrm{P}=\mathrm{GRAPH}\left(\right.$ month, $\mathrm{mgL}^{-1}$ ) (0.00, 0.077), (1.00, 0.0577), (2.00, 0.0188), (3.00, 0.0209), (4.00, 0.0174), (5.00, 0.013), (6.00, 0.0169), (7.00, 0.0254), (8.00, 0.0169), (9.00, 0.0132), (10.0, 0.0096), (11.0, 0.0276), (12.0, 0.0453)

Validation $\mathrm{pH}=\mathrm{GRAPH}(\mathrm{month}, \mathrm{pH}$ units) (0.00, 8.48), (1.00, 8.77), (2.00, 8.43), (3.00, 9.41), (4.00, 9.46), (5.00, 9.28), (6.00, 9.15), (7.00, 9.52), (8.00, 9.45), (9.00, 8.57), (10.0, 8.37), (11.0, 9.17), $(12.0,8.26)$

Validation PHOTPER $=$ GRAPH $($ time $-12 \times$ int $($ time $/ 12))$ (0.00, 578), (1.00, 640), (2.00, 732), (3.00, 807), (4.00, 867), (5.00, 902), (6.00, 890), (7.00, 825), (8.00, 734), (9.00, 679), (10.0, 579), (11.0, 561), (12.0, 590)

Validation SALIN $=$ GRAPH(month, $\mathrm{mgL}^{-1}$ ) (0.00, 2.33), (1.00, 1.50), (2.00, 18.3), (3.00, 20.3), (4.00, 16.8), (5.00, 28.2), (6.00, 30.3), (7.00, 27.8), (8.00, 24.7), (9.00, 28.0), (10.0, 25.3), (11.0, 5.80), $(12.0,6.60)$

Validation SILIC $=$ GRAPH(month, $\left.\mathrm{mgL}^{-1}\right)$ (0.00, 1.64), (1.00, 1.63), (2.00, 0.185), (3.00, 0.294), (4.00, 0.349), (5.00, 0.344), (6.00, 0.244), (7.00, 0.21), (8.00, 0.256), (9.00, 0.617), (10.0, 0.638), (11.0, 1.16), $(12.0,2.20)$

Validation TEMP $=\mathrm{GRAPH}\left(\right.$ month,$\left.{ }^{\circ} \mathrm{C}\right)$ (0.00, 13.0), (1.00, 9.00), (2.00, 19.7), (3.00, 20.7), (4.00, 21.0), (5.00, 23.0), (6.00, 22.0), (7.00, 20.0), (8.00, 25.7), (9.00, 14.7), (10.0, 15.7), (11.0, 9.70), $(12.0,8.10)$

Other functions

CPREC $=$ if Stochastic ON OFF $=1$ then RANDOM CPREC else Validation CPREC

$\mathrm{NH} 4=$ if Stochastic ON OFF = 1 then RANDOM NH4 else Validation $\mathrm{NH} 4$

NTA = if Stochastic ON OFF $=1$ then RANDOM NTA else Validation NTA

NTI $=$ if Stochastic ON OFF $=1$ then RANDOM NTI else Validation NTI

$\mathrm{O} 2$ = if Stochastic ON OFF $=1$ then RANDOM O2 else Validation $\mathrm{O} 2$

$\mathrm{OM}=$ if Stochastic $\mathrm{ON}$ OFF $=1$ then RANDOM OM else Validation $\mathrm{OM}$

$\mathrm{P}=$ if Stochastic $\mathrm{ON}$ OFF $=1$ then RANDOM P else Validation $\mathrm{P}$

Periodicity $=$ time $-12 \times \operatorname{int}($ time $/ 12)$

$\mathrm{pH}=$ if Stochastic ON OFF $=1$ then RANDOM pH else Validation $\mathrm{pH}$

PHOTPER $=$ if Stochastic ON OFF $=1$ then RANDOM PHOTPER else Validation PHOTPER

SALIN $=$ if Stochastic ON OFF $=1$ then RANDOM SALIN else Validation SALIN 
Appendix A (Continued)

SILIC $=$ if Stochastic ON OFF $=1$ then RANDOM SILIC else Validation SILIC

TEMP $=$ if Stochastic ON OFF $=1$ then RANDOM TEMP else Validation TEMP

CPREC

Apr $=$ RANDOM(MinCPRECApr,MaxCPRECApr)

CPREC

Aug $=$ RANDOM(MinCPRECAug,MaxCPRECAug) CPREC

Dec $=$ RANDOM(MinCPRECDec,MaxCPRECDec $)$

CPREC Feb = RANDOM(MinCPRECFeb,MaxCPRECFeb)

CPREC Jan = RANDOM(MinCPRECJan,MaxCPRECJan)

CPREC Jul = RANDOM(MinCPRECJul,MaxCPRECJul)

CPREC Jun = RANDOM(MinCPRECJun,MaxCPRECJun)

CPREC

Mar $=$ RANDOM(MinCPRECMar,MaxCPRECMar) CPREC

May = RANDOM(MinCPRECMay,MaxCPRECMay)

CPREC

Nov $=$ RANDOM(MinCPRECNov,MaxCPRECNov)

CPREC Oct $=$ RANDOM(MinCPRECOct,MaxCPRECOct $)$

CPREC proj Apr $=$ if periodicity $=4$ then $\mathrm{CPREC} \mathrm{Apr}$ else 0

CPREC proj Aug $=$ if periodicity $=8$ then CPREC Aug else 0

CPREC proj Dec $=$ if periodicity $=0$ then CPREC Dec else 0

CPREC proj Feb $=$ if periodicity $=2$ then CPREC Feb else 0

CPREC proj Jan $=$ if periodicity $=1$ then CPREC Jan else 0

CPREC proj Jul $=$ if periodicity $=7$ then CPREC Jul else 0

CPREC proj Jun $=$ if periodicity $=6$ then CPREC Jun else 0

CPREC proj Mar $=$ if periodicity $=3$ then CPREC Mar else 0

CPREC proj May $=$ if periodicity $=5$ then CPREC May else 0

CPREC proj Nov $=$ if periodicity $=11$ then CPREC Nov else 0

CPREC proj Oct $=$ if periodicity $=10$ then CPREC Oct else 0

CPREC proj Sept $=$ if periodicity $=9$ then CPREC Sept else 0

CPREC

Sept $=$ RANDOM(MinCPRECSept,MaxCPRECSept)

NH4 Apr $=$ if RANDOM CPREC $\leq$ NPREC then RANDOM(DMinNH4Apr,DMaxNH4Apr) else RANDOM(WMinNH4Apr,WMaxNH4Apr)

NH4 Aug = if RANDOM CPREC $\leq$ NPREC then RANDOM(DMinNH4Aug,DMaxNH4Aug) else RANDOM(WMinNH4Aug,WMaxNH4Aug)

NH4 Dec $=$ if RANDOM CPREC $\leq$ NPREC then RANDOM(DMinNH4Dec,DMaxNH4Dec) else RANDOM(WMinNH4Dec,WMaxNH4Dec)
Appendix A (Continued)

$\mathrm{NH} 4 \mathrm{Feb}=$ if RANDOM CPREC $\leq$ NPREC then RANDOM(DMinNH4Feb,DMaxNH4Feb) else RANDOM(WMinNH4Feb,WMaxNH4Feb)

NH4 Jan $=$ if RANDOM CPREC $\leq$ NPREC then RANDOM(DMinNH4Jan,DMaxNH4Jan) else RANDOM(WMinNH4Jan,WMaxNH4Jan)

$\mathrm{NH} 4 \mathrm{Jul}=$ if RANDOM CPREC $\leq$ NPREC then RANDOM(DMinNH4Jul,DMaxNH4Jul) else RANDOM(WMinNH4Jul,WMaxNH4Jul)

NH4 Jun $=$ if RANDOM CPREC $\leq$ NPREC then RANDOM(DMinNH4Jun,DMaxNH4Jun) else RANDOM(WMinNH4Jun,WMaxNH4Jun)

NH4 Mar $=$ if RANDOM CPREC $\leq$ NPREC then RANDOM(DMinNH4Mar,DMaxNH4Mar) else RANDOM(WMinNH4Mar,WMaxNH4Mar)

NH4 May $=$ if RANDOM CPREC $\leq$ NPREC then RANDOM(DMinNH4May,DMaxNH4May) else RANDOM(WMinNH4May,WMaxNH4May)

NH4 Nov $=$ if RANDOM CPREC $\leq$ NPREC then RANDOM(DMinNH4Nov,DMaxNH4Nov) else RANDOM(WMinNH4Nov,WMaxNH4Nov)

$\mathrm{NH} 4$ Oct $=$ if RANDOM CPREC $\leq$ NPREC then RANDOM(DMinNH4Oct,DMaxNH4Oct) else RANDOM(WMinNH4Oct,WMaxNH4Oct)

$\mathrm{NH} 4$ proj Apr $=$ if periodicity $=4$ then $\mathrm{NH} 4$ Apr else 0 $\mathrm{NH} 4$ proj Aug $=$ if periodicity $=8$ then $\mathrm{NH} 4$ Aug else 0 $\mathrm{NH} 4$ proj Dec $=$ if periodicity $=0$ then NH4 Dec else 0 $\mathrm{NH} 4$ proj Feb $=$ if periodicity $=2$ then NH4 Feb else 0 $\mathrm{NH} 4$ proj Jan $=$ if periodicity $=1$ then $\mathrm{NH} 4$ Jan else 0 $\mathrm{NH} 4$ proj Jul $=$ if periodicity $=7$ then $\mathrm{NH} 4$ Jul else 0 $\mathrm{NH} 4$ proj Jun $=$ if periodicity $=6$ then NH4 Jun else 0 $\mathrm{NH} 4$ proj Mar $=$ if periodicity $=3$ then NH4 Mar else 0 $\mathrm{NH} 4$ proj May $=$ if periodicity $=5$ then NH4 May else 0

NH4 proj Nov $=$ if periodicity $=11$ then NH4 Nov else 0

NH4 proj Oct $=$ if periodicity $=10$ then NH4 Oct else 0 $\mathrm{NH} 4$ proj Sept $=$ if periodicity $=9$ then $\mathrm{NH} 4$ Sept else 0

NH4 Sept $=$ if RANDOM CPREC $\leq$ NPREC then RANDOM(DMinNH4Sept,DMaxNH4Sept) else RANDOM(WMinNH4Sept,WMaxNH4Sept)

NTA Apr $=$ if RANDOM CPREC $\leq$ NPREC then RANDOM(DMinNTAApr,DMaxNTAApr) else RANDOM(WMinNTAApr,WMaxNTAApr)

NTA Aug $=$ if RANDOM CPREC $\leq$ NPREC then RANDOM(DMinNTAAug,DMaxNTAAug) else RANDOM(WMinNTAAug,WMaxNTAAug)

NTA Dec $=$ if RANDOM CPREC $\leq$ NPREC then RANDOM(DMinNTADec,DMaxNTADec) else RANDOM(WMinNTADec,WMaxNTADec)

NTA Feb $=$ if RANDOM CPREC $\leq$ NPREC then RANDOM(DMinNTAFeb,DMaxNTAFeb) else RANDOM(WMinNTAFeb,WMaxNTAFeb)

NTA Jan $=$ if RANDOM CPREC $\leq$ NPREC then RANDOM(DMinNTAJan,DMaxNTAJan) else RANDOM(WMinNTAJan,WMaxNTAJan) 
Appendix A (Continued)

NTA Jul $=$ if RANDOM CPREC $\leq$ NPREC then RANDOM(DMinNTAJul,DMaxNTAJul) else RANDOM(WMinNTAJul,WMaxNTAJul)

NTA Jun $=$ if RANDOM CPREC $\leq$ NPREC then RANDOM(DMinNTAJun,DMaxNTAJun) else RANDOM(WMinNTAJun,WMaxNTAJun) NTA Mar $=$ if RANDOM CPREC $\leq$ NPREC then RANDOM(DMinNTAMar,DMaxNTAMar) else RANDOM(WMinNTAMar,WMaxNTAMar)

NTA May $=$ if RANDOM CPREC $\leq$ NPREC then RANDOM(DMinNTAMay,DMaxNTAMay) else RANDOM(WMinNTAMay,WMaxNTAMay)

NTA Nov $=$ if RANDOM CPREC $\leq$ NPREC then RANDOM(DMinNTANov,DMaxNTANov) else RANDOM(WMinNTANov,WMaxNTANov) NTA Oct $=$ if RANDOM CPREC $\leq$ NPREC then RANDOM(DMinNTAOct,DMaxNTAOct) else RANDOM(WMinNTAOct,WMaxNTAOct) NTA proj Apr $=$ if periodicity $=4$ then NTA Apr else 0 NTA proj Aug $=$ if periodicity $=8$ then NTA Aug else 0 NTA proj Dec $=$ if periodicity $=0$ then NTA Dec else 0 NTA proj Feb $=$ if periodicity $=2$ then NTA Feb else 0 NTA proj Jan $=$ if periodicity $=1$ then NTA Jan else 0 NTA proj Jul $=$ if periodicity $=7$ then NTA Jul else 0 NTA proj Jun $=$ if periodicity $=6$ then NTA Jun else 0 NTA proj Mar $=$ if periodicity $=3$ then NTA Mar else 0 NTA proj May $=$ if periodicity $=5$ then NTA May else 0

NTA proj Nov $=$ if periodicity $=11$ then NTA Nov else 0

NTA proj Oct $=$ if periodicity $=10$ then NTA Oct else 0 NTA proj Sept $=$ if periodicity $=9$ then NTA Sept else 0

NTA Sept $=$ if RANDOM CPREC $\leq$ NPREC then RANDOM(DMinNTASept,DMaxNTASept) else RANDOM(WMinNTASept,WMaxNTASept)

NTI Apr $=$ if RANDOM CPREC $\leq$ NPREC then RANDOM(DMinNTIApr,DMaxNTIApr) else RANDOM(WMinNTIApr,WMaxNTIApr) NTI Aug $=$ if RANDOM CPREC $\leq$ NPREC then RANDOM(DMinNTIAug,DMaxNTIAug) else RANDOM(WMinNTIAug,WMaxNTIAug)

NTI Dec $=$ if RANDOM CPREC $\leq$ NPREC then RANDOM(DMinNTIDec,DMaxNTIDec) else RANDOM(WMinNTIDec,WMaxNTIDec)

NTI Feb $=$ if RANDOM CPREC $\leq$ NPREC then RANDOM(DMinNTIFeb,DMaxNTIFeb) else RANDOM(WMinNTIFeb,WMaxNTIFeb)

NTI Jan $=$ if RANDOM CPREC $\leq$ NPREC then RANDOM(DMinNTIJan,DMaxNTIJan) else RANDOM(WMinNTIJan,WMaxNTIJan) NTI Jul $=$ if RANDOM CPREC $\leq$ NPREC then RANDOM(DMinNTIJul,DMaxNTIJul) else RANDOM(WMinNTIJul,WMaxNTIJul) NTI Jun $=$ if RANDOM CPREC $\leq$ NPREC then RANDOM(DMinNTIJun,DMaxNTIJun) else RANDOM(WMinNTIJun,WMaxNTIJun)
Appendix A (Continued)

NTI Mar $=$ if RANDOM CPREC $\leq$ NPREC then RANDOM(DMinNTIMar,DMaxNTIMar) else RANDOM(WMinNTIMar,WMaxNTIMar)

NTI May $=$ if RANDOM CPREC $\leq$ NPREC then RANDOM(DMinNTIMay,DMaxNTIMay) else RANDOM(WMinNTIMay,WMaxNTIMay)

NTI Nov $=$ if RANDOM CPREC $\leq$ NPREC then RANDOM(DMinNTINov,DMaxNTINov) else RANDOM(WMinNTINov,WMaxNTINov)

NTI Oct $=$ if RANDOM CPREC $\leq$ NPREC then RANDOM(DMinNTIOct,DMaxNTIOct) else RANDOM(WMinNTIOct,WMaxNTIOct)

NTI proj Apr $=$ if periodicity $=4$ then NTI Apr else 0 NTI proj Aug $=$ if periodicity $=8$ then NTI Aug else 0 NTI proj Dec $=$ if periodicity $=0$ then NTI Dec else 0 NTI proj Feb $=$ if periodicity $=2$ then NTI Feb else 0 NTI proj Jan $=$ if periodicity $=1$ then NTI Jan else 0 NTI proj Jul $=$ if periodicity $=7$ then NTI Jul else 0 NTI proj Jun $=$ if periodicity $=6$ then NTI Jun else 0 NTI proj Mar $=$ if periodicity $=3$ then NTI Mar else 0 NTI proj May $=$ if periodicity $=5$ then NTI May else 0 NTI proj Nov $=$ if periodicity $=11$ then NTI Nov else 0 NTI proj Oct $=$ if periodicity $=10$ then NTI Oct else 0 NTI proj Sept $=$ if periodicity $=9$ then NTI Sept else 0 NTI Sept $=$ if RANDOM CPREC $\leq$ NPREC then RANDOM(DMinNTISept,DMaxNTISept) else RANDOM(WMinNTISept,WMaxNTISept) O2 Apr = if RANDOM CPREC $\leq$ NPREC then RANDOM(DMinO2Apr,DMaxO2Apr) else RANDOM(WMinO2Apr,WMaxO2Apr)

O2 Aug = if RANDOM CPREC $\leq$ NPREC then RANDOM(DMinO2Aug,DMaxO2Aug) else RANDOM(WMinO2Aug,WMaxO2Aug)

O2 Dec = if RANDOM CPREC $\leq$ NPREC then RANDOM(DMinO2Dec,DMaxO2Dec) else RANDOM(WMinO2Dec,WMaxO2Dec)

O2 Feb $=$ if RANDOM CPREC $\leq$ NPREC then RANDOM(DMinO2Feb,DMaxO2Feb) else RANDOM(WMinO2Feb,WMaxO2Feb) O2 Jan = if RANDOM CPREC $\leq$ NPREC then RANDOM(DMinO2Jan,DMaxO2Jan) else RANDOM(WMinO2Jan,WMaxO2Jan)

O2 Jul = if RANDOM CPREC $\leq$ NPREC then RANDOM(DMinO2Jul,DMaxO2Jul) else RANDOM(WMinO2Jul,WMaxO2Jul)

O2 Jun = if RANDOM CPREC $\leq$ NPREC then RANDOM(DMinO2Jun,DMaxO2Jun) else RANDOM(WMinO2Jun,WMaxO2Jun)

O2 $\mathrm{Mar}=$ if RANDOM CPREC $\leq$ NPREC then RANDOM(DMinO2Mar,DMaxO2Mar) else RANDOM(WMinO2Mar,WMaxO2Mar)

O2 May = if RANDOM CPREC $\leq$ NPREC then RANDOM(DMinO2May,DMaxO2May) else RANDOM(WMinO2May,WMaxO2May)

O2 Nov = if RANDOM CPREC $\leq$ NPREC then RANDOM(DMinO2Nov,DMaxO2Nov) else RANDOM(WMinO2Nov,WMaxO2Nov) 
Appendix A (Continued)

O2 Oct $=$ if RANDOM CPREC $\leq$ NPREC then RANDOM(DMinO2Oct,DMaxO2Oct) else RANDOM(WMinO2Oct,WMaxO2Oct)

$\mathrm{O} 2$ proj $\mathrm{Apr}=$ if periodicity $=4$ then $\mathrm{O} 2 \mathrm{Apr}$ else 0 $\mathrm{O} 2$ proj Aug $=$ if periodicity $=8$ then $\mathrm{O} 2 \mathrm{Aug}$ else 0 $\mathrm{O} 2$ proj $\mathrm{Dec}=$ if periodicity $=0$ then $\mathrm{O} 2 \mathrm{Dec}$ else 0 $\mathrm{O} 2$ proj Jul $=$ if periodicity $=7$ then $\mathrm{O} 2 \mathrm{Jul}$ else 0 $\mathrm{O} 2$ proj Jun $=$ if periodicity $=6$ then $\mathrm{O} 2$ Jun else 0 $\mathrm{O} 2$ proj Mar $=$ if periodicity $=3$ then $\mathrm{O} 2$ Mar else 0 $\mathrm{O} 2$ proj May $=$ if periodicity $=5$ then $\mathrm{O} 2$ May else 0 $\mathrm{O} 2$ proj Nov $=$ if periodicity $=11$ then $\mathrm{O} 2$ Nov else 0 $\mathrm{O} 2$ proj Oct $=$ if periodicity $=10$ then $\mathrm{O} 2$ Oct else 0 $\mathrm{O} 2$ proj Sept $=$ if periodicity $=9$ then $\mathrm{O} 2$ Sept else 0 O2 Sept $=$ if RANDOM CPREC $\leq$ NPREC then RANDOM(DMinO2Sept,DMaxO2Sept) else RANDOM(WMinO2Sept,WMaxO2Sept) OM Apr $=$ if RANDOM CPREC $\leq$ NPREC then RANDOM(DMinOMApr,DMaxOMApr) else RANDOM(WMinOMApr,WMaxOMApr) OM Aug = if RANDOM CPREC $\leq$ NPREC then RANDOM(DMinOMAug,DMaxOMAug) else RANDOM(WMinOMAug,WMaxOMAug)

OM Dec $=$ if RANDOM CPREC $\leq$ NPREC then RANDOM(DMinOMDec,DMaxOMDec) else RANDOM(WMinOMDec,WMaxOMDec)

$\mathrm{OM} F \mathrm{Fe}=$ if RANDOM CPREC $\leq$ NPREC then RANDOM(DMinOMFeb,DMaxOMFeb) else RANDOM(WMinOMFeb,WMaxOMFeb)

$\mathrm{OM} J a n=$ if RANDOM CPREC $\leq$ NPREC then RANDOM(DMinOMJan,DMaxOMJan) else RANDOM(WMinOMJan,WMaxOMJan) OM Jul = if RANDOM CPREC $\leq$ NPREC then RANDOM(DMinOMJul,DMaxOMJul) else RANDOM(WMinOMJul,WMaxOMJul) OM Jun $=$ if RANDOM CPREC $\leq$ NPREC then RANDOM(DMinOMJun,DMaxOMJun) else RANDOM(WMinOMJun,WMaxOMJun) OM Mar $=$ if RANDOM CPREC $\leq$ NPREC then RANDOM(DMinOMMar,DMaxOMMar) else RANDOM(WMinOMMar,WMaxOMMar) OM May $=$ if RANDOM CPREC $\leq$ NPREC then RANDOM(DMinOMMay,DMaxOMMay) else RANDOM(WMinOMMay,WMaxOMMay) OM Nov $=$ if RANDOM CPREC $\leq$ NPREC then RANDOM(DMinOMNov,DMaxOMNov) else RANDOM(WMinOMNov,WMaxOMNov) OM Oct $=$ if RANDOM CPREC $\leq$ NPREC then RANDOM(DMinOMOct,DMaxOMOct) else RANDOM(WMinOMOct,WMaxOMOct) OM proj Apr $=$ if periodicity $=4$ then $\mathrm{OM}$ Apr else 0 $\mathrm{OM}$ proj $\mathrm{Aug}=$ if periodicity $=8$ then $\mathrm{OM}$ Aug else 0 $\mathrm{OM}$ proj $\mathrm{Dec}=$ if periodicity $=0$ then $\mathrm{OM}$ Dec else 0 $\mathrm{OM}$ proj $\mathrm{Feb}=$ if periodicity $=2$ then $\mathrm{OM}$ Feb else 0 $\mathrm{OM}$ proj Jan $=$ if periodicity $=1$ then $\mathrm{OM}$ Jan else 0 $\mathrm{OM}$ proj Jul $=$ if periodicity $=7$ then $\mathrm{OM}$ Jul else 0 OM proj Jun $=$ if periodicity $=6$ then OM Jun else 0 OM proj Mar $=$ if periodicity $=3$ then $\mathrm{OM}$ Mar else 0 $\mathrm{OM}$ proj May $=$ if periodicity $=5$ then $\mathrm{OM}$ May else 0

\section{Appendix A (Continued)}

OM proj Nov $=$ if periodicity $=11$ then $\mathrm{OM}$ Nov else 0 OM proj Oct $=$ if periodicity $=10$ then OM Oct else 0 OM proj Sept $=$ if periodicity $=9$ then OM Sept else 0 OM Sept $=$ if RANDOM CPREC $\leq$ NPREC then RANDOM(DMinOMSept,DMaxOMSept) else RANDOM(WMinOMSept,WMaxOMSept) $\mathrm{pH}$ Apr $=$ if RANDOM CPREC $\leq$ NPREC then RANDOM(DMinpHApr,DMaxpHApr) else RANDOM(WMinpHApr,WMaxpHApr)

$\mathrm{pH}$ Aug $=$ if RANDOM CPREC $\leq$ NPREC then RANDOM(DMinpHAug,DMaxpHAug) else RANDOM(WMinpHAug,WMaxpHAug)

$\mathrm{pH}$ Dec $=$ if RANDOM CPREC $\leq$ NPREC then RANDOM(DMinpHDec,DMaxpHDec) else RANDOM(WMinpHDec,WMaxpHDec) $\mathrm{pH} F \mathrm{Fe}=$ if $\mathrm{RANDOM}$ CPREC $\leq$ NPREC then RANDOM(DMinpHFeb,DMaxpHFeb) else RANDOM(WMinpHFeb,WMaxpHFeb) $\mathrm{pH}$ Jan $=$ if RANDOM CPREC $\leq$ NPREC then RANDOM(DMinpHJan,DMaxpHJan) else RANDOM(WMinpHJan,WMaxpHJan) $\mathrm{pH}$ Jul $=$ if RANDOM CPREC $\leq$ NPREC then RANDOM(DMinpHJul,DMaxpHJul) else RANDOM(WMinpHJul,WMaxpHJul) $\mathrm{pH}$ Jun $=$ if RANDOM CPREC $\leq$ NPREC then RANDOM(DMinpHJun,DMaxpHJun) else RANDOM(WMinpHJun,WMaxpHJun) $\mathrm{pH}$ Mar $=$ if RANDOM CPREC $\leq$ NPREC then RANDOM(DMinpHMar,DMaxpHMar) else RANDOM(WMinpHMar,WMaxpHMar) $\mathrm{pH}$ May $=$ if RANDOM CPREC $\leq$ NPREC then RANDOM(DMinpHMay,DMaxpHMay) else RANDOM(WMinpHMay,WMaxpHMay) $\mathrm{pH}$ Nov $=$ if RANDOM CPREC $\leq$ NPREC then RANDOM(DMinpHNov,DMaxpHNov) else RANDOM(WMinpHNov,WMaxpHNov) $\mathrm{pH}$ Oct $=$ if RANDOM CPREC $\leq$ NPREC then RANDOM(DMinpHOct,DMaxpHOct) else RANDOM(WMinpHOct,WMaxpHOct) $\mathrm{pH}$ proj Apr $=$ if periodicity $=4$ then $\mathrm{pH}$ Apr else 0 $\mathrm{pH}$ proj $\mathrm{Aug}=$ if periodicity $=8$ then $\mathrm{pH}$ Aug else 0 $\mathrm{pH}$ proj Dec $=$ if periodicity $=0$ then $\mathrm{pH}$ Dec else 0 $\mathrm{pH}$ proj Feb $=$ if periodicity $=2$ then $\mathrm{pH}$ Feb else 0 $\mathrm{pH}$ proj Jan $=$ if periodicity $=1$ then $\mathrm{pH}$ Jan else 0 $\mathrm{pH}$ proj Jul $=$ if periodicity $=7$ then $\mathrm{pH}$ Jul else 0 $\mathrm{pH}$ proj Jun $=$ if periodicity $=6$ then $\mathrm{pH}$ Jun else 0 $\mathrm{pH}$ proj Mar $=$ if periodicity $=3$ then $\mathrm{pH}$ Mar else 0 $\mathrm{pH}$ proj May $=$ if periodicity $=5$ then $\mathrm{pH}$ May else 0 $\mathrm{pH}$ proj Nov $=$ if periodicity $=11$ then $\mathrm{pH}$ Nov else 0 $\mathrm{pH}$ proj Oct $=$ if periodicity $=10$ then $\mathrm{pH}$ Oct else 0 $\mathrm{pH}$ proj Sept $=$ if periodicity $=9$ then $\mathrm{pH}$ Sept else 0 $\mathrm{pH}$ Sept $=$ if RANDOM CPREC $\leq$ NPREC then

RANDOM(DMinpHSept,DMaxpHSept) else RANDOM(WMinpHSept,WMaxpHSept)

$\mathrm{P}$ Apr $=$ if RANDOM CPREC $\leq$ NPREC then RANDOM(DMinPApr,DMaxPApr) else RANDOM(WMinPApr,WMaxPApr) 
Appendix A (Continued)

$P$ Aug $=$ if RANDOM CPREC $\leq$ NPREC then RANDOM(DMinPAug,DMaxPAug) else RANDOM(WMinPAug,WMaxPAug)

$P$ Dec $=$ if RANDOM CPREC $\leq$ NPREC then RANDOM(DMinPDec,DMaxPDec) else RANDOM(WMinPDec,WMaxPDec)

$P$ Feb $=$ if RANDOM CPREC $\leq$ NPREC then RANDOM(DMinPFeb,DMaxPFeb) else RANDOM(WMinPFeb,WMaxPFeb)

$P$ Jan $=$ if RANDOM CPREC $\leq$ NPREC then RANDOM(DMinPJan,DMaxPJan) else RANDOM(WMinPJan,WMaxPJan)

$P$ Jul $=$ if RANDOM CPREC $\leq$ NPREC then RANDOM(DMinPJul,DMaxPJul) else RANDOM(WMinPJul,WMaxPJul)

$P$ Jun $=$ if RANDOM CPREC $\leq$ NPREC then RANDOM(DMinPJun,DMaxPJun) else RANDOM(WMinPJun,WMaxPJun)

P Mar $=$ if RANDOM CPREC $\leq$ NPREC then RANDOM(DMinPMar,DMaxPMar) else RANDOM(WMinPMar,WMaxPMar)

P May $=$ if RANDOM CPREC $\leq$ NPREC then RANDOM(DMinPMay,DMaxPMay) else RANDOM(WMinPMay,WMaxPMay)

$\mathrm{P}$ Nov $=$ if RANDOM CPREC $\leq$ NPREC then RANDOM(DMinPNov,DMaxPNov) else RANDOM(WMinPNov,WMaxPNov)

P Oct $=$ if RANDOM CPREC $\leq$ NPREC then RANDOM(DMinPOct,DMaxPOct) else RANDOM(WMinPOct,WMaxPOct)

$\mathrm{P}$ proj Apr $=$ if periodicity $=4$ then $\mathrm{P}$ Apr else 0 P proj Aug $=$ if periodicity $=8$ then $P$ Aug else 0 $P$ proj Dec $=$ if periodicity $=0$ then $P$ Dec else 0 $\mathrm{P}$ proj Feb $=$ if periodicity $=2$ then $\mathrm{P}$ Feb else 0 $\mathrm{P}$ proj Jan $=$ if periodicity $=1$ then $\mathrm{P}$ Jan else 0 $P$ proj Jul $=$ if periodicity $=7$ then $P$ Jul else 0 $P$ proj Jun $=$ if periodicity $=6$ then $P$ Jun else 0 $P$ proj Mar $=$ if periodicity $=3$ then $P$ Mar else 0 $P$ proj May $=$ if periodicity $=5$ then $P$ May else 0 $P$ proj Nov $=$ if periodicity $=11$ then $P$ Nov else 0 P proj Oct $=$ if periodicity $=10$ then $\mathrm{P}$ Oct else 0 P proj Sept $=$ if periodicity $=9$ then $\mathrm{P}$ Sept else 0

P Sept $=$ if RANDOM CPREC $\leq$ NPREC then RANDOM(DMinPSept,DMaxPSept) else RANDOM(WMinPSept,WMaxPSept)

RANDOM CPREC $=$ CPREC proj Dec + CPREC proj Jan + CPREC proj Feb + CPREC proj Mar + CPREC proj Apr + CPREC proj May + CPREC proj Jun + CPREC proj Jul + CPREC proj Aug + CPREC proj Sept + CPREC proj Oct + CPREC proj Nov RANDOM NH4 = NH4 proj Dec + NH4 proj Jan + NH4 proj Feb + NH4 proj Mar + NH4 proj Apr $+\mathrm{NH} 4$ proj May + NH4 proj Jun + NH4 proj Jul + NH4 proj $\mathrm{Aug}+\mathrm{NH} 4$ proj Sept $+\mathrm{NH} 4$ proj Oct $+\mathrm{NH} 4$ proj Nov RANDOM NTA = NTA proj Dec + NTA proj Jan + NTA proj Feb + NTA proj Mar + NTA proj Apr + NTA proj May + NTA proj Jun + NTA proj Jul + NTA proj Aug + NTA proj Sept + NTA proj Oct + NTA proj Nov
Appendix A (Continued)

RANDOM NTI = NTI proj Dec + NTI proj Jan + NTI proj Feb + NTI proj Mar + NTI proj Apr + NTI proj May + NTI proj Jun + NTI proj Jul + NTI proj Aug + NTI proj Sept + NTI proj Oct + NTI proj Nov RANDOM O2 = O2 proj Dec + O2 proj Jan + O2 proj $\mathrm{Feb}+\mathrm{O} 2$ proj $\mathrm{Mar}+\mathrm{O} 2$ proj Apr $+\mathrm{O} 2$ proj May + O2 proj Jun + O2 proj Jul + O2 proj Aug + O2 proj Sept + O2 proj Oct + O2 proj Nov

RANDOM OM = OM proj Dec + OM proj Jan + OM proj $\mathrm{Feb}+\mathrm{OM}$ proj $\mathrm{Mar}+\mathrm{OM}$ proj Apr + OM proj May + OM proj Jun + OM proj Jul + OM proj $\mathrm{Aug}+\mathrm{OM}$ proj Sept + OM proj Oct + OM proj Nov RANDOM $\mathrm{P}=\mathrm{P}$ proj Dec $+\mathrm{P}$ proj Jan $+\mathrm{P}$ proj $\mathrm{Feb}+\mathrm{P}$ proj Mar + P proj Apr + P proj May + P proj Jun + P proj Jul + P proj Aug + P proj Sept + P proj Oct + P proj Nov

RANDOM $\mathrm{pH}=\mathrm{pH}$ proj Dec $+\mathrm{pH}$ proj Jan $+\mathrm{pH}$ proj $\mathrm{Feb}+\mathrm{pH}$ proj $\mathrm{Mar}+\mathrm{pH}$ proj Apr $+\mathrm{pH}$ proj May $+\mathrm{pH}$ proj Jun + pH proj Jul + pH proj Aug + pH proj Sept + pH proj Oct + pH proj Nov

RANDOM PHOTPER $=$ PHOTPER proj Dec + PHOTPER proj Jan + PHOTPER proj Feb + PHOTPER proj Mar + PHOTPER proj Apr + PHOTPER proj May + PHOTPER proj Jun + PHOTPER proj Jul + PHOTPER proj Aug + PHOTPER proj Sept + PHOTPER proj Oct + PHOTPER proj Nov RANDOM SALIN = SALIN proj Dec + SALIN proj Jan + SALIN proj Feb + SALIN proj Mar + SALIN proj Apr + SALIN proj May + SALIN proj Jun + SALIN proj Jul + SALIN proj Aug + SALIN proj Sept + SALIN proj Oct + SALIN proj Nov RANDOM SILIC = SILIC proj Dec + SILIC proj Jan + SILIC proj Feb + SILIC proj Mar + SILIC proj Apr + SILIC proj May + SILIC proj Jun + SILIC proj Jul + SILIC proj Aug + SILIC proj Sept + SILIC proj Oct + SILIC proj Nov

RANDOM TEMP = TEMP proj Dec + TEMP proj Jan + TEMP proj Feb + TEMP proj Mar + TEMP proj Apr + TEMP proj May + TEMP proj Jun + TEMP proj Jul + TEMP proj Aug + TEMP proj Sept + TEMP proj Oct + TEMP proj Nov

SALIN Apr $=$ if RANDOM CPREC $\leq$ NPREC then RANDOM(DMinSALINApr,DMaxSALINApr) else RANDOM(WMinSALINApr,WMaxSALINApr) SALIN Aug = if RANDOM CPREC $\leq$ NPREC then RANDOM(DMinSALINAug,DMaxSALINAug) else RANDOM(WMinSALINAug,WMaxSALINAug)

SALIN Dec $=$ if RANDOM CPREC $\leq$ NPREC then RANDOM(DMinSALINDec,DMaxSALINDec) else RANDOM(WMinSALINDec,WMaxSALINDec)

SALIN Feb $=$ if RANDOM CPREC $\leq$ NPREC then RANDOM(DMinSALINFeb,DMaxSALINFeb) else RANDOM(WMinSALINFeb,WMaxSALINFeb) SALIN Jan $=$ if RANDOM CPREC $\leq$ NPREC then RANDOM(DMinSALINJan,DMaxSALINJan) else RANDOM(WMinSALINJan,WMaxSALINJan) 
Appendix A (Continued)

SALIN Jul $=$ if RANDOM CPREC $\leq$ NPREC then RANDOM(DMinSALINJul,DMaxSALINJul) else RANDOM(WMinSALINJul,WMaxSALINJul)

SALIN Jun $=$ if RANDOM CPREC $\leq$ NPREC then RANDOM(DMinSALINJun,DMaxSALINJun) else RANDOM(WMinSALINJUn,WMaxSALINJun)

SALIN Mar $=$ if RANDOM CPREC $\leq$ NPREC then RANDOM(DMinSALINMar,DMaxSALINMar) else RANDOM(WMinSALINMar,WMaxSALINMar)

SALIN May $=$ if RANDOM CPREC $\leq$ NPREC then RANDOM(DMinSALINMay,DMaxSALINMay) else RANDOM(WMinSALINMay,WMaxSALINMay)

SALIN Nov $=$ if RANDOM CPREC $\leq$ NPREC then RANDOM(DMinSALINNov,DMaxSALINNov) else RANDOM(WMinSALINNov,WMaxSALINNov)

SALIN Oct $=$ if RANDOM CPREC $\leq$ NPREC then RANDOM(DMinSALINOct,DMaxSALINOct) else RANDOM(WMinSALINOct,WMaxSALINOct)

SALIN proj $\mathrm{Apr}=$ if periodicity $=4$ then SALIN Apr else 0

SALIN proj Aug $=$ if periodicity $=8$ then SALIN Aug else 0

SALIN proj $\mathrm{Dec}=$ if periodicity $=0$ then SALIN Dec else 0

SALIN proj Feb $=$ if periodicity $=2$ then SALIN Feb else 0

SALIN proj Jan $=$ if periodicity $=1$ then SALIN Jan else 0

SALIN proj Jul $=$ if periodicity $=7$ then SALIN Jul else 0

SALIN proj Jun $=$ if periodicity $=6$ then SALIN Jun else 0

SALIN proj Mar $=$ if periodicity $=3$ then SALIN Mar else 0

SALIN proj May $=$ if periodicity $=5$ then SALIN May else 0

SALIN proj Nov $=$ if periodicity $=11$ then SALIN Nov else 0

SALIN proj Oct $=$ if periodicity $=10$ then SALIN Oct else 0

SALIN proj Sept $=$ if periodicity $=9$ then SALIN Sept else 0

SALIN Sept $=$ if RANDOM CPREC $\leq$ NPREC then RANDOM(DMinSALINSept,DMaxSALINSept) else RANDOM(WMinSALINSept,WMaxSALINSept)

SILIC Apr $=$ if RANDOM CPREC $\leq$ NPREC then RANDOM(DMinSILICApr,DMaxSILICApr) else RANDOM(WMinSILICApr,WMaxSILICApr)

SILIC Aug $=$ if RANDOM CPREC $\leq$ NPREC then RANDOM(DMinSILICAug,DMaxSILICAug) else RANDOM(WMinSILICAug,WMaxSILICAug)

SILIC DeC $=$ if RANDOM CPREC $\leq$ NPREC then RANDOM(DMinSILICDec,DMaxSILICDec) else RANDOM(WMinSILICDec,WMaxSILICDec) SILIC Feb $=$ if RANDOM CPREC $\leq$ NPREC then RANDOM(DMinSILICFeb,DMaxSILICFeb) else RANDOM(WMinSILICFeb,WMaxSILICFeb)
Appendix A (Continued)

SILIC Jan $=$ if RANDOM CPREC $\leq$ NPREC then RANDOM(DMinSILICJan,DMaxSILICJan) else RANDOM(WMinSILICJan,WMaxSILICJan)

SILIC Jul $=$ if RANDOM CPREC $\leq$ NPREC then RANDOM(DMinSILICJul,DMaxSILICJul) else RANDOM(WMinSILICJul,WMaxSILICJul)

SILIC Jun $=$ if RANDOM CPREC $\leq$ NPREC then RANDOM(DMinSILICJun,DMaxSILICJun) else RANDOM(WMinSILICJun,WMaxSILICJun)

SILIC Mar $=$ if RANDOM CPREC $\leq$ NPREC then RANDOM(DMinSILICMar,DMaxSILICMar) else RANDOM(WMinSILICMar,WMaxSILICMar)

SILIC May $=$ if RANDOM CPREC $\leq$ NPREC then RANDOM(DMinSILICMay,DMaxSILICMay) else RANDOM(WMinSILICMay,WMaxSILICMay)

SILIC Nov $=$ if RANDOM CPREC $\leq$ NPREC then RANDOM(DMinSILICNov,DMaxSILICNov) else RANDOM(WMinSILICNov,WMaxSILICNov)

SILIC Oct $=$ if RANDOM CPREC $\leq$ NPREC then RANDOM(DMinSILICOct,DMaxSILICOct) else RANDOM(WMinSILICOct,WMaxSILICOct)

SILIC proj Apr $=$ if periodicity $=4$ then SILIC Apr else 0

SILIC proj Aug $=$ if periodicity $=8$ then SILIC Aug else 0

SILIC proj Dec $=$ if periodicity $=0$ then SILIC Dec else 0

SILIC proj Feb $=$ if periodicity $=2$ then SILIC Feb else 0

SILIC proj Jan $=$ if periodicity $=1$ then SILIC Jan else 0 SILIC proj Jul $=$ if periodicity $=7$ then SILIC Jul else 0 SILIC proj Jun $=$ if periodicity $=6$ then SILIC Jun else 0 SILIC proj Mar $=$ if periodicity $=3$ then SILIC Mar else 0

SILIC proj May $=$ if periodicity $=5$ then SILIC May else 0

SILIC proj Nov $=$ if periodicity $=11$ then SILIC Nov else 0

SILIC proj Oct $=$ if periodicity $=10$ then SILIC Oct else 0

SILIC proj Sept $=$ if periodicity $=9$ then SILIC Sept else 0

SILIC Sept $=$ if RANDOM CPREC $\leq$ NPREC then RANDOM(DMinSILICSept,DMaxSILICSept) else RANDOM(WMinSILICSept,WMaxSILICSept)

TEMP Apr $=$ if RANDOM CPREC $\leq$ NPREC then RANDOM(DMinTEMPApr,DMaxTEMPApr) else RANDOM(WMinTEMPApr,WMaxTEMPApr)

TEMP Aug $=$ if RANDOM CPREC $\leq$ NPREC then RANDOM(DMinTEMPAug,DMaxTEMPAug) else RANDOM(WMinTEMPAug,WMaxTEMPAug)

TEMP DeC $=$ if RANDOM CPREC $\leq$ NPREC then RANDOM(DMinTEMPDec,DMaxTEMPDec) else RANDOM(WMinTEMPDec,WMaxTEMPDec)

TEMP Feb $=$ if RANDOM CPREC $\leq$ NPREC then RANDOM(DMinTEMPFeb,DMaxTEMPFeb) else RANDOM(WMinTEMPFeb,WMaxTEMPFeb) 
Appendix A (Continued)

TEMP Jan $=$ if RANDOM CPREC $\leq$ NPREC then RANDOM(DMinTEMPJan,DMaxTEMPJan) else RANDOM(WMinTEMPJan,WMaxTEMPJan)

TEMP Jul $=$ if RANDOM CPREC $\leq$ NPREC then RANDOM(DMinTEMPJul,DMaxTEMPJul) else RANDOM(WMinTEMPJul,WMaxTEMPJul) TEMP Jun $=$ if RANDOM CPREC $\leq$ NPREC then RANDOM(DMinTEMPJun,DMaxTEMPJun) else RANDOM(WMinTEMPJun,WMaxTEMPJun)

TEMP Mar $=$ if RANDOM CPREC $\leq$ NPREC then RANDOM(DMinTEMPMar,DMaxTEMPMar) else RANDOM(WMinTEMPMar,WMaxTEMPMar) TEMP May $=$ if RANDOM CPREC $\leq$ NPREC then RANDOM(DMinTEMPMay,DMaxTEMPMay) else RANDOM(WMinTEMPMay,WMaxTEMPMay)

TEMP Nov $=$ if RANDOM CPREC $\leq$ NPREC then RANDOM(DMinTEMPNov,DMaxTEMPNov) else RANDOM(WMinTEMPNov,WMaxTEMPNov) TEMP Oct $=$ if RANDOM CPREC $\leq$ NPREC then RANDOM(DMinTEMPOct,DMaxTEMPOct) else RANDOM(WMinTEMPOct,WMaxTEMPOct)

TEMP proj Apr $=$ if periodicity $=4$ then TEMP Apr else 0

TEMP proj Aug $=$ if periodicity $=8$ then TEMP Aug else 0

TEMP proj Dec $=$ if periodicity $=0$ then TEMP Dec else 0

TEMP proj Feb $=$ if periodicity $=2$ then TEMP Feb else 0

TEMP proj Jan $=$ if periodicity $=1$ then TEMP Jan else 0

TEMP proj Jul $=$ if periodicity $=7$ then TEMP Jul else 0 TEMP proj Jun $=$ if periodicity $=6$ then TEMP Jun else 0

TEMP proj Mar $=$ if periodicity $=3$ then TEMP Mar else 0

TEMP proj May $=$ if periodicity $=5$ then TEMP May else 0

TEMP proj Nov $=$ if periodicity $=11$ then TEMP Nov else 0

TEMP proj Oct $=$ if periodicity $=10$ then TEMP Oct else 0

TEMP proj Sept $=$ if periodicity $=9$ then TEMP Sept else 0

TEMP Sept $=$ if RANDOM CPREC $\leq$ NPREC then RANDOM(DMinTEMPSept,DMaxTEMPSept) else RANDOM(WMinTEMPSept,WMaxTEMPSept)

IntTIMERES $=$ if CPREC $\leq$ NPREC then DIntTIMERES else WTIMERES

MaXTIMERES $=$ if CPREC $\leq$ NPREC then DMAXTIMERES else WTIMERES

MinTIMERES $=$ if $C P R E C \leq$ NPREC then DMinTIMERES else WTIMERES

TIMERES = TIMERES proj Min + TIMERES proj Int + TIMERES proj Max

TIMERES proj Int $=$ if periodicity $=9$ then IntTIMERES else 0
Appendix A (Continued)

TIMERES proj Max $=$ if periodicity $>=0$ and Periodicity $<=5$ or Periodicity $>=10$ then MaxTIMERES else 0

TIMERES proj Min $=$ if Periodicity $>5$ and Periodicity $<9$ then MinTIMERES else 0

Constants

Stochastic ON OFF $=1$

Management option $=1$

SUB $=0.188$

DIntTIMERES $=26.4$

DMAXTIMERES $=52.8$

DMINTIMERES $=19.2$

WTIMERES $=20$

MaxCPRECApr $=200$

MaxCPRECAug $=58.3$

MaxCPRECDec $=321.6$

MaxCPRECFeb $=153.7$

MaxCPRECJan $=336$

MaxCPRECJul $=22.3$

MaxCPRECJun $=74.2$

MaxCPRECMar $=119.6$

MaxCPRECMay $=221.2$

MaxCPRECNov $=224.7$

MaxCPRECOct $=323.6$

MaxCPRECSept $=122.3$

MinCPRECApr $=18$

MinCPRECAug $=0.1$

MinCPRECDec $=2.8$

$\mathrm{MinCPRECFeb}=0$

MinCPRECJan $=9.6$

MinCPRECJul $=0$

MinCPRECJun $=0$

MinCPRECMar $=13.2$

MinCPRECMay $=28.2$

MinCPRECNov $=16.1$

MinCPRECOct $=3.5$

MinCPRECSept $=8.2$

DMaxNH4Apr $=0.337$

DMaxNH4Aug $=0.830$

DMaxNH4Dec $=0.490$

$\mathrm{DMaxNH} 4 \mathrm{Feb}=0.370$

DMaxNH4Jan $=0.602$

DMaxNH4Jul $=0.500$

DMaxNH4Jun $=0.320$

DMaxNH4Mar $=0.300$

$\mathrm{DMaxNH} 4 \mathrm{May}=0.280$

DMaxNH4Nov $=0.715$

DMaxNH4Oct $=0.423$

DMaxNH4Sept $=0.340$

DMinNH4Apr $=0.038$

$\mathrm{DMinNH} 4 \mathrm{Aug}=0.004$

$\mathrm{DMinNH} 4 \mathrm{Dec}=0.038$

$\mathrm{DMinNH4Feb}=0.036$

DMinNH4Jan $=0.047$

DMinNH4Jul $=0.045$

DMinNH4Jun $=0.117$

DMinNH4Mar $=0.046$ 
Appendix A (Continued)

DMinNH4May $=0.056$

DMinNH4Nov $=0.102$

DMinNH4Oct $=0.290$

$\mathrm{DMinNH} 4$ Sept $=0.030$

WMaxNH4Apr $=0.119$

WMaxNH4Aug $=0.451$

WMaxNH4Dec $=0.311$

$\mathrm{WMaxNH} 4 \mathrm{Feb}=0.330$

WMaxNH4Jan $=0.767$

WMaxNH4Jul $=0.099$

WMaxNH4Jun $=0.235$

WMaxNH4Mar $=0.268$

WMaxNH4May $=0.310$

$\mathrm{WMaxNH} 4 \mathrm{Nov}=0.400$

$\mathrm{WMaxNH} 4 \mathrm{Oct}=0.650$

WMaxNH4Sept $=0.320$

WMinNH4Apr $=0.119$

WMinNH4Aug $=0.113$

WMinNH4Dec $=0.100$

WMinNH4Feb $=0.330$

WMinNH4Jan $=0.043$

WMinNH4Jul $=0.073$

WMinNH4Jun $=0.235$

WMinNH4Mar $=0.075$

WMinNH4May $=0.092$

$\mathrm{WMinNH} 4 \mathrm{Nov}=0.037$

$\mathrm{WMinNH} 4 \mathrm{Oct}=0.072$

WMinNH4Sept $=0.045$

DMaxNTAApr $=0.070$

DMaxNTAAug $=0.051$

DMaxNTADec $=0.184$

DMaxNTAFeb $=0.612$

DMaxNTAJan $=0.299$

DMaxNTAJul $=0.108$

DMaxNTAJun $=0.190$

DMaxNTAMar $=0.163$

DMaxNTAMay $=0.590$

DMaxNTANov $=0.226$

DMaxNTAOct $=0.011$

DMaxNTASept $=0.078$

DMinNTAApr $=0.005$

DMinNTAAug $=0.003$

DMinNTADec $=0.023$

DMinNTAFeb $=0.025$

DMinNTAJan $=0.096$

DMinNTAJul $=0.003$

DMinNTAJun $=0.001$

DMinNTAMar $=0.020$

DMinNTAMay $=0.006$

DMinNTANov $=0.047$

DMinNTAOct $=0.007$

DMinNTASept $=0.011$

WMaxNTAApr $=0.089$

WMaxNTAAug $=0.048$

WMaxNTADec $=0.525$

WMaxNTAFeb $=0.088$

WMaxNTAJan $=1.068$

WMaxNTAJul $=0.021$
Appendix A (Continued)

WMaxNTAJun $=0.034$

WMaxNTAMar $=0.187$

WMaxNTAMay $=0.099$

WMaxNTANov $=0.196$

WMaxNTAOct $=0.409$

WMaxNTASept $=0.068$

WMinNTAApr $=0.089$

WMinNTAAug $=0.003$

WMinNTADec $=0.091$

WMinNTAFeb $=0.088$

WMinNTAJan $=0.184$

WMinNTAJul $=0.011$

WMinNTAJun $=0.034$

WMinNTAMar $=0.015$

WMinNTAMay $=0.013$

WMinNTANov $=0.058$

WMinNTAOct $=0.006$

WMinNTASept $=0.010$

DMaxNTIApr $=0.019$

DMaxNTIAug $=0.014$

DMaxNTIDec $=0.073$

DMaxNTIFeb $=0.066$

DMaxNTIJan $=0.124$

DMaxNTIJul $=0.015$

DMaxNTIJun $=0.020$

DMaxNTIMar $=0.034$

DMaxNTIMay $=0.025$

DMaxNTINov $=0.040$

DMaxNTIOct $=0.019$

DMaxNTISept $=0.028$

DMinNTIApr $=0.003$

DMinNTIAug $=0.006$

DMinNTIDec $=0.016$

DMinNTIFeb $=0.011$

DMinNTIJan $=0.015$

DMinNTIJul $=0.006$

DMinNTIJun $=0.004$

DMinNTIMar $=0.006$

DMinNTIMay $=0.003$

DMinNTINov $=0.019$

DMinNTIOct $=0.007$

DMinNTISept $=0.005$

WMaxNTIApr $=0.027$

WMaxNTIAug $=0.036$

WMaxNTIDec $=0.048$

$\mathrm{WMaxNTIFeb}=0.017$

WMaxNTIJan $=0.068$

WMaxNTIJul $=0.020$

WMaxNTIJun $=0.015$

WMaxNTIMar $=0.051$

WMaxNTIMay $=0.021$

WMaxNTINov $=0.055$

WMaxNTIOct $=0.032$

WMaxNTISept $=0.032$

WMinNTIApr $=0.027$

WMinNTIAug $=0.005$

WMinNTIDec $=0.016$

WMinNTIFeb $=0.017$ 
Appendix A (Continued)

WMinNTIJan $=0.015$

WMinNTIJul $=0.008$

WMinNTIJun $=0.015$

WMinNTIMar $=0.027$

WMinNTIMay $=0.004$

WMinNTINov $=0.012$

WMinNTIOct $=0.008$

WMinNTISept $=0.005$

DMaxO2Apr $=16.1$

DMaxO2Aug $=17.6$

$\mathrm{DMaxO} 2 \mathrm{Dec}=19.50$

$\mathrm{DMaxO} 2 \mathrm{Feb}=16.2$

$\mathrm{DMaxO}$ Jan $=44.80$

DMaxO2Jul $=17.2$

DMaxO2Jun $=32.6$

$\mathrm{DMaxO} 2 \mathrm{Mar}=22.6$

$\mathrm{DMaxO} 2 \mathrm{May}=22$

$\mathrm{DMaxO} 2 \mathrm{Nov}=13.4$

DMaxO2Oct $=13.7$

DMaxO2Sept $=14.7$

DMinO2Apr $=5.84$

$\mathrm{DMinO} 2 \mathrm{Aug}=7.10$

$\mathrm{DMinO} 2 \mathrm{Dec}=9.70$

$\mathrm{DMinO} 2 \mathrm{Feb}=10$

DMinO2Jan $=9.60$

DMinO2Jul $=8.70$

DMinO2Jun $=8.65$

DMinO2Mar $=8.97$

DMinO2May $=6.62$

$\mathrm{DMinO} 2 \mathrm{Nov}=7.74$

$\mathrm{DMinO} 2 \mathrm{Oct}=7.40$

DMinO2Sept $=8.51$

$\mathrm{WMaxO} 2 \mathrm{Apr}=8.54$

$\mathrm{WMaxO} 2 \mathrm{Aug}=16.30$

$\mathrm{WMaxO} 2 \mathrm{Dec}=9.60$

$\mathrm{WMaxO} 2 \mathrm{Feb}=11.90$

$\mathrm{WMaxO} 2 \mathrm{Jan}=11.60$

$\mathrm{WMaxO} 2 \mathrm{Jul}=14.20$

WMaxO2Jun $=13.27$

WMaxO2Mar $=15.87$

$\mathrm{WMaxO} 2 \mathrm{May}=14.50$

$\mathrm{WMaxO} 2 \mathrm{Nov}=15.75$

WMaxO2Oct $=13.50$

WMaxO2Sept $=19.80$

$\mathrm{WMinO} 2 \mathrm{Apr}=8.54$

$\mathrm{WMinO} 2 \mathrm{Aug}=8.51$

$\mathrm{WMinO} 2 \mathrm{Dec}=5.50$

$\mathrm{WMinO} 2 \mathrm{Feb}=11.90$

WMinO2Jan $=10$

$\mathrm{WMinO} 2 \mathrm{Jul}=8.78$

WMinO2Jun $=13.27$

WMinO2Mar $=6.07$

WMinO2May $=10.75$

WMinO2Nov $=9.30$

WMinO2Oct $=10.50$

$\mathrm{WMinO} 2 \mathrm{Sept}=6.80$

DMaxOMApr $=6.77$
Appendix A (Continued)

DMaxOMAug $=5.25$

$\mathrm{DMaxOMDec}=4.17$

DMaxOMFeb $=3.45$

DMaxOMJan $=3.87$

DMaxOMJul $=5.16$

DMaxOMJun $=6.6$

DMaxOMMar $=5.32$

DMaxOMMay $=3.8$

$\mathrm{DMaxOMNov}=3.291$

DMaxOMOct $=4.15$

DMaxOMSept $=3.02$

DMinOMApr $=1.620$

DMinOMAug $=1.96$

DMinOMDec $=1.9$

DMinOMFeb $=1.92$

DMinOMJan $=2.4$

DMinOMJul $=1.892$

DMinOMJun $=2.48$

DMinOMMar $=1.617$

DMinOMMay $=1.18$

DMinOMNov $=1.86$

DMinOMOct $=3.93$

DMinOMSept $=1.82$

WMaxOMApr $=2.312$

WMaxOMAug $=2.4$

WMaxOMDec $=2.100$

$\mathrm{WMaxOMFeb}=2.60$

$\mathrm{WMaxOMJan}=4$

$\mathrm{WMaxOMJul}=2.000$

WMaxOMJun $=1.920$

$\mathrm{WMaxOMMar}=3.580$

$\mathrm{WMaxOMMay}=4.760$

$\mathrm{WMaxOMNov}=4.500$

$\mathrm{WMaxOMOct}=4.800$

WMaxOMSept $=5.120$

WMinOMApr $=2.312$

WMinOMAug $=1.450$

WMinOMDec $=1.440$

$\mathrm{WMinOMFeb}=2.6$

WMinOMJan $=1.900$

WMinOMJul $=1.700$

WMinOMJun $=1.920$

WMinOMMar $=1.200$

WMinOMMay $=1.850$

WMinOMNov $=1.880$

WMinOMOct $=1.900$

WMinOMSept $=1.281$

DMaxPApr $=0.073$

DMaxPAug $=0.121$

DMaxPDec $=0.062$

$\mathrm{DMaxPFeb}=0.074$

DMaxPJan $=0.064$

DMaxPJul $=0.112$

DMaxPJun $=0.087$

DMaxPMar $=0.071$

DMaxPMay $=0.062$

DMaxPNov $=0.076$

DMaxPOct $=0.067$ 
Appendix A (Continued)

DMaxPSept $=0.115$

DMinPApr $=0.009$

DMinPAug $=0.032$

DMinPDec $=0.022$

DMinPFeb $=0.017$

DMinPJan $=0.040$

DMinPJul $=0.017$

DMinPJun $=0.013$

DMinPMar $=0.014$

DMinPMay $=0.025$

DMinPNov $=0.010$

DMinPOct $=0.013$

DMinPSept $=0.017$

WMaxPApr $=0.038$

WMaxPAug $=0.111$

$\mathrm{WMaxPDec}=0.034$

$\mathrm{WMaxPFeb}=0.012$

WMaxPJan $=0.087$

WMaxPJul $=0.084$

WMaxPJun $=0.040$

$\mathrm{WMaxPMar}=0.095$

$\mathrm{WMaxPMay}=0.052$

WMaxPNov $=0.061$

WMaxPOct $=0.148$

WMaxPSept $=0.084$

WMinPApr $=0.038$

WMinPAug $=0.025$

WMinPDec $=0.028$

$\mathrm{WMinPFeb}=0.012$

WMinPJan $=0.029$

WMinPJul $=0.025$

WMinPJun $=0.040$

WMinPMar $=0.019$

WMinPMay $=0.015$

WMinPNov $=0.007$

WMinPOct $=0.022$

WMinPSept $=0.020$

DMaxpHApr $=9.41$

DMaxpHAug $=8.69$

DMaxpHDec $=9.19$

DMaxpHFeb $=9.09$

DMaxpHJan $=8.68$

DMaxpHJul $=9.15$

DMaxpHJun $=9.31$

DMaxpHMar $=9.50$

DMaxpHMay $=8.90$

DMaxpHNov $=9.06$

DMaxpHOct $=8.62$

DMaxpHSept $=9.45$

DMinpHApr $=8.27$

DMinpHAug $=8.07$

DMinpHDec $=7.50$

DMinpHFeb $=8.02$

DMinpHJan $=8.26$

DMinpHJul = 7.86

DMinpHJun $=8.02$

DMinpHMar $=7.91$

DMinpHMay $=8.18$
Appendix A (Continued)

DMinpHNov $=7.83$

DMinpHOct $=8.57$

DMinpHSept $=8.30$

WMaxpHApr $=8.13$

WMaxpHAug $=9.52$

WMaxpHDec $=9.17$

$\mathrm{WMaxpHFeb}=8.96$

WMaxpHJan $=9.04$

WMaxpHJul $=8.32$

WMaxpHJun $=8.60$

WMaxpHMar $=9.03$

WMaxpHMay $=9.46$

$\mathrm{WMaxpHNov}=8.62$

WMaxpHOct $=8.94$

WMaxpHSept $=8.98$

WMinpHApr $=8.13$

WMinpHAug $=8.39$

WMinpHDec $=8.20$

WMinpHFeb $=8.96$

WMinpHJan $=8.37$

WMinpHJul $=8.16$

WMinpHJun $=8.60$

WMinpHMar $=8.13$

WMinpHMay $=7.92$

WMinpHNov $=8.04$

WMinpHOct $=7.92$

WMinpHSept $=8.60$

DMaxSALINApr $=30$

DMaxSALINAug $=30$

DMaxSALINDec $=26.7$

DMaxSALINFeb $=26$

DMaxSALINJan $=31$

DMaxSALINJul $=32.6$

DMaxSALINJun $=34$

DMaxSALINMar $=30.7$

DMaxSALINMay $=34$

DMaxSALINNov $=29.4$

DMaxSALINOct $=28$

DMaxSALINSept $=35.5$

DMinSALINApr $=20.2$

DMinSALINAug $=22$

DMinSALINDec $=13.4$

DMinSALINFeb $=1.5$

DMinSALINJan $=6.6$

DMinSALINJul $=25$

DMinSALINJun $=13.05$

DMinSALINMar $=12.9$

DMinSALINMay $=26.2$

DMinSALINNOV $=19$

DMinSALINOct $=22.5$

DMinSALINSept $=14.4$

WMaxSALINApr $=21.50$

WMaxSALINAug $=28.9$

WMaxSALINDec $=15.50$

WMaxSALINFeb $=7$

WMaxSALINJan $=5.5$

WMaxSALINJul $=30.1$

WMaxSALINJun $=27$ 
Appendix A (Continued)

WMaxSALINMar $=22.60$

WMaxSALINMay $=27.90$

WMaxSALINNov $=28.00$

WMaxSALINOct $=31.30$

WMaxSALINSept $=31.30$

WMinSALINApr $=21.50$

WMinSALINAug $=26.9$

WMinSALINDec $=0$

WMinSALINFeb $=7$

WMinSALINJan $=2.33$

WMinSALINJul $=29.5$

WMinSALINJUn $=27$

WMinSALINMar $=16.20$

WMinSALINMay $=16.80$

WMinSALINNOV $=16$

WMinSALINOct $=9.5$

WMinSALINSept $=27.7$

DMaxSILICApr $=0.966$

DMaxSILICAug $=1.000$

DMaxSILICDec $=1.289$

DMaxSILICFeb $=1.625$

DMaxSILICJan $=2.201$

DMaxSILICJul $=0.785$

DMaxSILICJun $=1.352$

DMaxSILICMar $=0.810$

DMaxSILICMay $=0.815$

DMaxSILICNov $=1.077$

DMaxSILICOct $=0.638$

DMaxSILICSept $=0.861$

DMinSILICApr $=0.195$

DMinSILICAug $=0.126$

DMinSILICDec $=0.210$

DMinSILICFeb $=0.345$

DMinSILICJan $=0.580$

DMinSILICJul $=0.244$

DMinSILICJun $=0.200$

DMinSILICMar $=0.271$

DMinSILICMay $=0.399$

DMinSILICNov $=0.638$

DMinSILICOct $=0.617$

DMinSILICSept $=0.256$

WMaxSILICApr $=1.466$

WMaxSILICAug $=1.134$

WMaxSILICDec $=2.239$

WMaxSILICFeb $=0.318$

WMaxSILICJan $=2.457$

WMaxSILICJul $=0.769$

WMaxSILICJun $=0.651$

WMaxSILICMar $=1.613$

WMaxSILICMay $=0.792$

WMaxSILICNov $=0.844$

WMaxSILICOct $=1.382$

WMaxSILICSept $=1.054$

WMinSILICApr $=1.466$

WMinSILICAug $=0.210$

WMinSILICDec $=0.386$

WMinSILICFeb $=0.318$
Appendix A (Continued)

WMinSILICJan $=0.870$

WMinSILICJul $=0.433$

WMinSILICJun $=0.651$

WMinSILICMar $=0.185$

WMinSILICMay $=0.195$

WMinSILICNOV $=0.580$

WMinSILICOct $=0.540$

WMinSILICSept $=0.160$

DMaxTEMPApr $=22.9$

DMaxTEMPAug $=29$

DMaxTEMPDec $=18.5$

DMaxTEMPFeb $=17.4$

DMaxTEMPJan $=15.3$

DMaxTEMPJul $=32.6$

DMaxTEMPJun $=31.4$

DMaxTEMPMar $=22$

DMaxTEMPMay $=26$

DMaxTEMPNov $=18.5$

DMaxTEMPOct $=19$

DMaxTEMPSept $=25.7$

DMinTEMPApr $=15.5$

DMinTEMPAug $=19.1$

DMinTEMPDec $=12.2$

DMinTEMPFeb $=9$

DMinTEMPJan $=8.1$

DMinTEMPJul $=22$

DMinTEMPJun $=23$

DMinTEMPMar $=13.25$

DMinTEMPMay $=16$

DMinTEMPNov $=13.9$

DMinTEMPOct $=14.7$

DMinTEMPSept $=17.8$

WMaxTEMPApr $=14.10$

WMaxTEMPAug $=28.4$

WMaxTEMPDec $=13.4$

$\mathrm{WMaxTEMPFeb}=19.5$

WMaxTEMPJan $=13.9$

WMaxTEMPJul $=29.2$

WMaxTEMPJun $=25.60$

WMaxTEMPMar $=20.9$

WMaxTEMPMay $=21$

WMaxTEMPNov $=20$

WMaXTEMPOct $=24.5$

WMaxTEMPSept $=27.6$

WMinTEMPApr $=14.1$

WMinTEMPAug $=20.00$

WMinTEMPDec $=9.7$

WMinTEMPFeb $=19.5$

WMinTEMPJan $=11$

WMinTEMPJul $=25.1$

WMinTEMPJun $=25.6$

WMinTEMPMar $=18.6$

WMinTEMPMay $=17.9$

WMinTEMPNov $=14.7$

WMinTEMPOct $=15.8$

WMinTEMPSept $=23.15$ 
Andreasen, J.K., O'Neill, R.V., Noss, R., Slosser, N.C., 2001. Considerations for the development of a terrestrial index of ecological integrity. Ecol. Indic. 1, 21-35.

Bamber, R.N., 1985. The autoecology of Cyathura carinata (Crustacea: Isopoda) in a cooling water discharge lagoon. J. Mar. Biol. Assoc. U.K. 65, 181-194.

Beisner, B.E., Haydon, D.T., Cuddington, K., 2003. Alternative stable stages in ecology. Front. Ecol. Environ. 1, 376-382. www.frontiersinecoly.org.

Broekhoven, E., Adriaenssens, V., Baets, B., Verdonschot, P., 2006. Fuzzy rule-based macroinvertebrate habitat suitability models for running waters. Ecol. Model. 198 (1/2), 71-84.

Brosse, S., Lek, S., Townsend, C.R., 2001. Abundance, diversity, and structure of freshwater invertebrates and fish communities: an artificial neural network approach. N. Z. J. Mar. Freshwater Res. 35, 135-145.

Cabecinha, E., Cortes, R., Cabral, J.A., 2004. Performance of a stochastic-dynamic modelling methodology for running waters ecological assessment. Ecol. Model. 175 (3), 303-317.

Cabral, J.A., Pardal, M.A., Lopes, R.J., Múrias, T., Marques, J.C., 1999. The impact of macroalgal blooms on the use of the intertidal area and feeding behaviour of waders (Charadrii) in the Mondego estuary (west Portugal). Acta Oecol. 20 (4), 417-427.

Cabral, J.A., Marques, J.C., Nielsen, S.N., 2001. Modelling mosquitofish (Gambusia holbrooki) responses to Genapol OXD-080, a non-ionic surfactant, in rice fields. Ecol. Eng. 16, 537-544.

Cabral, J.A., Rocha, A., Santos, M., Crespi, A.L., 2007. A stochastic dynamic methodology (SDM) to facilitate handling simple passerine indicators in the scope of the agri-environmental measures problematics. Ecol. Indic. 7, 34-47.

Cardoso, P.G., Lilleb $\varnothing$, A.I., Pardal, M.A., Ferreira, S.M., Marques, J.C., 2002. The effects of different primary producers on Hydrobia ulvae population dynamics: a case study in a temperate intertidal estuary. J. Exp. Mar. Biol. Ecol. 277 (2), 173-195.

Cardoso, P.G., Pardal, M.A., Raffaelli, D., Baeta, A., Marques, J.C., 2004a. Macroinvertebrate response to different species of macroalgal mats and the role of disturbance history. J. Exp. Mar. Biol. Ecol. 308, 207-220.

Cardoso, P.G., Pardal, M.A., Lilleb $\varnothing$, A.I., Ferreira, S.M., Raffaelli, D., Marques, J.C., 2004b. Dynamic changes in seagrass assemblages under eutrophication and implications for recovery. J. Exp. Mar. Biol. Ecol. 302, 233-248.

Cardoso, P.G., Brandão, A., Pardal, M.A., Raffaelli, D., Marques, J.C., 2005. The resilience of Hydrobia ulvae populations to anthropogenic and natural disturbances. Mar. Ecol. Prog. Ser. 289, 191-199.

Chaloupka, M., 2002. Stochastic simulation modelling of southern Great Barrier Reef green turtle population dynamics. Ecol. Model. 148, 79-109.

Cloern, J.E., 2001. Our evolving conceptual model of coastal eutrophication problem. Mar. Ecol. Prog. Ser. 210, 223-253.

Costanza, R., 1992. Towards an operational definition of ecosystem health. In: Costanza, R., Norton, B., Haskell, B. (Eds.), Ecosystem Health: New Goals for Environmental Management. Island Press, Washington, DC, pp. 239-256.

Costanza, R., Voinov, A., 2001. Modelling ecological and economic systems with STELLA: Part III. Ecol. Model. 143 (1/2), 1-7.

Costanza, R., Voinov, A., 2003. Introduction: spatially explicit landscape simulation models. In: Costanza, R., Voinov, A. (Eds.), Landscape Simulation Modeling: A Spatially Explicit, Dynamic Approach. Springer-Verlag, New York, pp. 3-20.

Džeroski, S., Grbovic, J., Walley, W.J., Kompare, B., 1997. Using machine learning techniques in the construction of models.
2. Data analysis with rule induction. Ecol. Model. 95 (1), 95-111.

Džeroski, S., Demšar, D., Grbovic, J., 2000. Predicting chemical parameters of river water quality from bioindicator data. Appl. Intell. 13, 7-17.

Dolbeth, M., Pardal, M.A., Lillebø, A.I., Azeiteiro, U., Marques, J.C., 2003. Short- and long-term effects of eutrophication on the secondary production of an intertidal macrobenthic community. Mar. Biol. 143, 1229-1238.

Dolbeth, M., Lillebø, A.I., Cardoso, P.G., Ferreira, S.M., Pardal, M.A., 2005. Annual production of estuarine fauna in different environmental conditions: an evaluation of the estimation methods. J. Exp. Mar. Biol. Ecol. 326, 115-127.

Ferreira, S.M., Pardal, M.A., Lillebø, A.I., Cardoso, P.G., Marques, J.C., 2004. Population dynamics of Cyathura carinata (Isopoda) in a eutrophic temperate estuary. Estuar. Coast. Shelf Sci. 61, 669-677.

Flindt, M.R., Kamp-Nielsen, L., Marques, J.C., Pardal, M.A., Bocci, M., Bendoricchio, G., Salomonsen, J., Nielsen, S.N., Jørgensen, S.E., 1997. Description of the three shallow estuaries: Mondego River (Portugal), Roskilde Fjord (Denmark) and the Lagoon of Venice (Italy). Ecol. Model. 102, 17-31.

Jørgensen, S.E., 1994. Models as instruments for combination of ecological theory and environmental practice. Ecol. Model. 75/76, 5-20.

Jørgensen, S.E., Bernardi, R., 1997. The application of a model with dynamic structure to simulate the effect of mass fish mortality on zooplankton structure in Lago di Annone. Hydrobiologia 356, 87-96.

Jørgensen, S.E., 1999. State-of-the-art of ecological modelling with emphasis on development of structural dynamic models. Ecol. Model. 120, 75-96.

Jørgensen, S.E. (Ed.), 2001. Fundamentals of Ecological Modelling, 3rd ed. Elsevier, Amsterdam.

Kamer, K., Boyle, K.A., Fong, P., 2001. Macroalgal bloom dynamics in a highly eutrophic southern California estuary. Estuaries 24 (4), 623-635.

Kareiva, P., Kingsolver, J.G., Huey, R.B., 1993. Biotic interactions and global change. Sinauer Associates, Sunderland, MA, USA.

Lillebø, A.I., Pardal, M.A., Marques, J.C., 1999. Population structure, dynamics and production of Hydrobia ulvae (Pennant) (Mollusca: Prosobranchia) along an eutrophication gradient in the Mondego estuary (Portugal). Acta Oecol. 20, 289-304.

Lilleb $\varnothing$, A.I., Neto, J.M., Martins, I., Verdelhos, T., Leston, S., Cardoso, P.G., Ferreira, S.M., Marques, J.C., Pardal, M.A., 2005. Management of shallow temperate estuary to control eutrophication: The effect of hydrodynamics on the system's nutrient loading. Estuar. Coast. Shelf Sci. 65, 697-707.

Lopes, R.J., Pardal, M.A., Marques, J.C., 2000. Impact of macroalgal blooms and wader predation on intertidal macroinvertebrates: experimental evidence from the Mondego estuary (Portugal). J. Exp. Mar. Biol. Ecol. 249, 165-179.

Lopes, R.J., Cabral, J.A., Múrias, T., Pacheco, C., Marques, J.C., 2002. Status and habitat use of waders in the Mondego estuary. In: Pardal, M.A., Marques, J.C., Graça, M.A. (Eds.), Aquatic Ecology of the Mondego River Basin. Global Importance of Local Experience. Imprensa da Universidade de Coimbra, pp. 219-230.

Lopes, R.J., Múrias, T., Cabral, J.A., Marques, J.C., 2005. A ten year study of variation, trends and seasonality of shorebird community in the Mondego estuary, Portugal. Waterbirds 28 (1), 8-18.

Lopes, R.J., Pardal, M.A., Múrias, T., Cabral, J.A., Marques, J.C., 2006. Influence of macroalgal mats on abundance and distribution of Dunlin Calidris alpina in estuaries: A long term approach. Mar. Ecol. Prog. Ser. 323, 11-20. 
Manel, S., Dias, J., Ormerod, S.J., 1999. Comparing discriminant analysis, neural networks and logistic regression for predicting species distributions: a case study with a Himalayan river bird. Ecol. Model. 120 (2/3), 337-347.

Marques, J.C., Martins, I., Teles-Ferreira, C., Cruz, S., 1994. Population dynamics, life history and production of Cyathura carinata (Krøyer) (Isopoda: Anthuridae) in the Mondego estuary, Portugal. J. Crustacean Biol. 14 (2), 258-272.

Marques, J.C., Pardal, M.A., Maranhão, P., 2002. Characterisation of the macroinvertebrate benthic communities in the Mondego estuary. In: Pardal, M.A., Marques, J.C., Graça, M.A. (Eds.), Aquatic Ecology of the Mondego River Basin. Global Importance of Local Experience. Imprensa da Universidade de Coimbra, pp. 169-197.

Marques, J.C., Nielsen, S.N., Pardal, M.A., Jørgensen, S.E., 2003. Impact of eutrophication and river management within a framework of ecosystem theories. Ecol. Model. 166, 147-168.

Martins, I., Marques, J.C., Jørgensen, S.E., Nielsen, S.N., 1997. Modelling the effects of green macroalgae blooms on the population dynamics of Cyathura carinata (Crustacea: Isopoda) in an eutrophied estuary. Ecol. Model. 102, 33-53.

Martins, I., Pardal, M.A., Lilleb $\varnothing$, A.I., Flindt, M.R., Marques, J.C., 2001. Hydrodinamics as a major factor controlling the occurrence of green macroalgal blooms in a eutrophic estuary: a case study on the influence of precipitation and river management. Estuar. Coast. Shelf Sci. 52, 165-177.

Múrias, T., Cabral, J.A., Marques, J.C., Goss-Custard, J.D., 1996. Short-term effects of intertidal macroalgal blooms on the macrohabitat selection and feeding behaviour of wading birds in the Mondego estuary (West Portugal). Estuar. Coast. Shelf Sci. 43, 677-688.

Múrias, T., Cabral, J.A., Lopes, R., Marques, J.C., 1997. Low water use of the mondego estuary (West Portugal) by waders. Ardeola 44, 79-91.

Múrias, T., Cabral, J.A., Lopes, I., Marques, J.C., 2002. Effects of eutrophication on waders (Aves: Charadrii) in the Mondego estuary: a multi-level approach. In: Pardal, M.A., Marques, J.C., Graça, M.A. (Eds.), Aquatic Ecology of the Mondego River Basin. Global Importance of Local Experience. Imprensa da Universidade de Coimbra, pp. 527-540.

Múrias, T., Cabral, J.A., Lopes, R.J., Pardal, M.A., Marques, J.C., Goss-Custard, J., 2005. Competition for feeding in waders: a case study in an estuary of south temperate Europe (Mondego, Portugal). Hydrobiologia 544, 155-166.

Neto, J.M., 2004. Nutrient Enrichment in a Temperate Macro-tidal System. Scenario Analysis and Contribution to Coastal Management. Ph.D. Thesis. University of Coimbra, 139 pp.

Norkko, A., Bonsdorff, E., Norkko, A., 2000. Drifting algal mats as an alternative habitat for benthic invertebrates: species specific responses to a transient resource. J. Exp. Mar. Biol. Ecol. 248, 79-104.

Oberdorf, T., Pont, D., Hugheny, B., Chessel, D., 2001. A probabilistic model characterizing fish assemblages of French rivers: a framework for environmental assessment. Freshwater Biol. 46, 399-415.

Patrício, J., Ulanowicz, R., Pardal, M.A., Marques, J.C., 2004. Ascendency as an ecological indicator: a case study of estuarine pulse eutrophication. Estuar. Coast. Shelf Sci. 60, 23-35.

Pardal, M.A., Marques, J.C., Metelo, I., Lillebø, A.I., Flindt, M.R., 2000. Impact of eutrophication on the life cycle, population dynamics and production of Ampithoe valida (Amphipoda) along an estuarine spatial gradient (Mondego estuary, Portugal). Mar. Ecol. Prog. Ser. 196, 207-219.
Pardal, M.A., Cardoso, P.G., Sousa, J.P., Marques, J.C., Raffaelli, D., 2004. Assessing environmental quality: a novel approach. Mar. Ecol. Prog. Ser. 267, 1-8.

Podani, J. (Ed.), 2000. Introduction to the Exploration of Multivariate Biological Data. Leiden, Backhuys, p. 407.

Raffaelli, D., Milne, H., 1987. An experimental investigation of the effects of shorebirds and flatfish predation on estuarine invertebrates. Estuar. Coast. Shelf Sci. 24, 1-13.

Raffaelli, D.G., Hull, S.C., Milne, H., 1989. Long-term changes in nutrients, weed mats and shorebirds in an estuarine system. Cahiers Biol. Mar. 30, 259-270.

Santos, M., Cabral, J.A., 2003. Development of a stochastic dynamic model for ecological indicators' prediction in changed Mediterranean agroecosystems of north-eastern Portugal. Ecol. Indic. 3, 285-303.

Santos, M., Vaz, C., Travassos, P., Cabral, J.A., 2007. Simulating the impact of socio-economic trends on threatened Iberian wolf populations (Canis lupus signatus) in North-eastern Portugal. Ecol. Indic. 7, 649-664.

Sfriso, A., Birkmeyer, T., Ghetti, P.F., 2001. Benthic macrofauna changes in areas of Venice lagoon populated by seagrasses or seaweeds. Mar. Environ. Res. 52, 323-349.

Silva-Santos, P.M., Pardal, M.A., Lopes, R.J., Múrias, T., Cabral, J.A., 2006. A Stochastic Dynamic Methodology (SDM) to the modelling of trophic interactions, with a focus on estuarine eutrophication scenarios. Ecol. Indic. 6, 394-408.

Sokal, R.R., Rohlf, F.J. (Eds.), 1995. Biometry, 3rd ed. W.H. Freeman and Company, New York.

Sola, J.C., Arzubialde, M., 1993. Dinámica de poblaciónes y biología de Cyathura carinata en el estuario del Bidasoa. Publicaciones Especiales Inst. Español Oceanogr. 11, 57-64.

Valiela, I., Rutecki, D., Fox, S., 2004. Salt marshes: biological controls of food webs in a diminishing environment. J. Exp. Mar. Biol. Ecol. 300, 131-159.

Van der Meer, J., Duin, R.N.M., Meininger, P.L., 1996. Statistical analysis of long-term monthly Oystercatcher Haematopus ostralegus counts. Ardea 84A, 39-55.

Verdelhos, T., Neto, J.M., Marques, J.C., Pardal, M.A., 2005. The effect of eutrophication abatement on the bivalve Scrobicularia plana. Estuar. Coast. Shelf Sci. 63, 261-268.

Voinov, A., Voinov, H., Costanza, R., 2001. Surface water flow in landscape models. 2. Patuxent watershed case study. Ecol. Model. 119, 211-230.

Walley, W.J., Džeroski, S., 1995. Biological monitoring: a comparison between Bayesian, neural and machine learning methods of water quality classification. In: Denzer, R., Schimak, G., Russell, D. (Eds.), Proceedings of the International Symposium on Environmental Software Systems, IFIP Conference Series. Chapman \& Hall, London.

Walley, W.J., Fontama, V.N., Martin, R.W., 1998. Applications of artificial intelligence in river quality surveys. R\&D Technical Report E52, Environment Agency, Bristol.

Walley, W.J., Fontama, V.N., 2000. New approaches to river quality classification based upon artificial intelligence. In: Furse, M.T., Wright, J.F. (Eds.), Assessing the Biological Quality of Fresh Waters: RIVPACS and Other Techniques. Freshwater Biological Association, Ambleside, UK.

Wooldridge, T.H., Callahan, R., 2000. The effects of a single freshwater release into the Kromme Estuary. Part 3. Estuarine zooplankton response. Water SA 26 (3), 311-318.

Zar, J.H. (Ed.), 1996. Biostatistical Analysis, 3rd ed. Prentice-Hall International Inc., Englewood Cliffs, NJ. 